2019-01

\title{
Deeper knowledge of shallow waters: reviewing the invertebrate fauna of southern African temporary wetlands
}

\section{Bird, MS}

http://hdl.handle.net/10026.1/12484

\subsection{7/s10750-018-3772-z.}

Hydrobiologia

Springer Verlag

All content in PEARL is protected by copyright law. Author manuscripts are made available in accordance with publisher policies. Please cite only the published version using the details provided on the item record or document. In the absence of an open licence (e.g. Creative Commons), permissions for further reuse of content should be sought from the publisher or author. 


\section{Deeper knowledge of shallow waters: reviewing the invertebrate fauna of 2 southern African temporary wetlands}

3 Matthew S. Bird, ${ }^{1 *}$ Musa C. Mlambo, ${ }^{2}$ Ryan J. Wasserman, ${ }^{3,4}$ Tatenda Dalu, ${ }^{5}$ Alexandra J.

4 Holland, ${ }^{2}$ Jenny A. Day, ${ }^{6}$ Martin H. Villet, ${ }^{7}$ David T. Bilton, ${ }^{8}$ Helen M. Barber-James,${ }^{2,7}$ Luc

5 Brendonck ${ }^{9,10}$

$6 \quad{ }^{1}$ Department of Zoology, University of Johannesburg, Auckland Park, Johannesburg 2006, South Africa

$7 \quad{ }^{2}$ Department of Freshwater Invertebrates, Albany Museum ${ }^{\dagger}$, Grahamstown 6140, South Africa

$8 \quad{ }^{3}$ South African Institute for Aquatic Biodiversity, Grahamstown 6140, South Africa

$9{ }^{4}$ Department of Biological Sciences and Biotechnology, Botswana International University of Science and

10 Technology, P. Bag 16, Palapye, Botswana

$11{ }^{5}$ Department of Ecology and Resource Management, University of Venda, Thohoyandou 0950, South Africa

$12{ }^{6}$ Institute of Water Studies, Department of Earth Sciences, University of the Western Cape, Bellville 7535, Cape 13 Town

$14 \quad{ }^{7}$ Department of Zoology and Entomology, Rhodes University, Grahamstown 6140, South Africa

$15{ }^{8}$ Marine Biology and Ecology Research Centre, School of Biological and Marine Sciences, University of 16 Plymouth, Plymouth PL4 8AA, UK

$17{ }^{9}$ Animal Ecology, Global Change and Sustainable Development, KU Leuven, Leuven B-3000, Belgium

$18{ }^{10}$ Research Unit for Environmental Sciences and Management, Potchefstroom Campus, North-West University, 19 Potchefstroom 2520, South Africa

\footnotetext{
* Corresponding author email: mattsbird@gmail.com

${ }^{\dagger}$ A Rhodes University affiliated institution
} 


\section{Abstract}

21 Temporary lentic wetlands are becoming increasingly recognised for their collective role in contributing to biodiversity at the landscape scale. In southern Africa, a region with a high density of such wetlands, information characterising the fauna of these systems is disparate and often obscurely published. Here we provide a collation and synthesis of published research on the aquatic invertebrate fauna inhabiting temporary lentic wetlands of the region. We expose the poor taxonomic knowledge of most groups, which makes it difficult to comment on patterns of richness and endemism. Only a few groups (e.g. large branchiopods, ostracods, copepods and cladocerans) appear to reach higher richness and/or endemicity in temporary wetlands compared to their permanent wetland counterparts. IUCN Red List information is lacking for most taxa, thus making it difficult to comment on the conservation status of much of the invertebrate fauna. However, except for a few specialist groups, many of the taxa inhabiting these environments appear to be habitat generalists that opportunistically exploit these waterbodies and this is hypothesized as one of the reasons why endemism appears to be low for most taxa. Given that taxonomy underpins ecology, the urgent need for more foundational taxonomic work on these systems becomes glaringly apparent.

\section{Keywords}

aquatic invertebrates; wetland invertebrates; ephemeral wetlands; temporary ponds; ephemeral ponds; pans; southern Africa; African wetlands

\section{Introduction}

Invertebrates dominate the faunas of temporary wetlands worldwide, in terms of species diversity, abundance and animal biomass (Williams, 2006). Insects and crustaceans, in particular, are ubiquitous in such systems. Temporary wetlands house a suite of uniquely specialized invertebrates (Wiggins et al., 1980; Collinson et al., 1995; Brucet et al., 2005;

46 Escalera-Vázquez \& Zambrano, 2010; Strachan et al., 2015) which are particularly

47 vulnerable to habitat and hydrological modifications (Calhoun et al., 2017; Dalu et al., 48 2017a). The southern African region, with its distinct climatic and geomorphic features, has 49 one of the highest densities of temporary depression wetlands (known locally as 'pans') worldwide (Goudie \& Wells, 1995). Reviews of the invertebrate fauna of temporary wetlands 
have been conducted for a number of regions globally (e.g. Batzer et al., 1999; Batzer \&

Boix, 2016), but not for southern Africa; as such, this study aims to fill the knowledge gap.

Southern Africa is generally defined as the area south of the Kunene River in the west and the Zambezi River in the east (including the countries of Botswana, Lesotho, Namibia, South Africa, Swaziland, Zimbabwe, and southern parts of Angola and Mozambique). These boundaries are referred to as 'the region' or 'the southern African region' throughout this review.

Providing a checklist of all the species within each invertebrate group known from temporary wetlands in the region is beyond the scope of this review and in many cases insufficient information is available. For certain groups, we summarise reported checklists and highlight gaps in taxonomic and ecological understanding. We review taxonomic and biodiversity studies pertaining to freshwater invertebrates in temporary lentic wetlands in the region, group-by-group. Our primary aim is to provide an overview of available information (taxonomic, faunistic and ecological) for each of the major invertebrate taxa found in temporary lentic wetlands in the region, highlighting major gaps in knowledge. The key adaptations that each invertebrate taxon has evolved to cope with desiccation are also briefly covered where such information exists. For general information on wetland invertebrate adaptations to drought, see Wiggins et al. (1980), Brendonck \& De Meester (2003), Williams (2006), Strachan et al. (2015) and Batzer \& Boix (2016).

\section{Methods}

A comprehensive review of all published material in peer-reviewed journals for the period 1960 to 2016 was conducted using a combination of the following terms: 'temporary', 'seasonal', 'ephemeral', 'vernal', 'endorheic', 'rock', 'rain', 'pond', 'pool', 'pan', 'tarn', 'depression', 'southern Africa', plus all the individual countries within it, and 'invertebrates', plus all the major taxa within. References to other important studies cited in the published material above were also referred to and in turn these were also searched thoroughly for further important cited work. In this way, the relevant literature has been comprehensively surveyed. Only those papers that tackled invertebrate populations or communities from wetland systems that temporarily dry up were included in the final list used for this review. However, in certain cases, there was no mention of whether the wetland was temporarily inundated or not. In such cases it was necessary to pay careful attention to the mention of or 
inference to flagship taxa (sensu De Roeck et al., 2007) or the adaptive traits to drying conditions (Lahr, 1997) as this would confirm the temporary nature of the wetland. The review aims to focus on lentic isolated depressional wetlands that are not connected to longitudinal watercourses (i.e. non-riverine systems). However, such specific habitat information is often not available for a given taxon, and thus we include taxa that have simply been recorded as occurring in temporary wetland environments, even if information on the specific nature of these environments is not available for the taxon in question.

The material from peer-reviewed journals was further complemented by consulting key texts in the 'grey literature' that contain comprehensive species lists, including the Water Research Commission's 'Guides to the Freshwater Invertebrates of Southern Africa' (relevant chapters are referenced separately throughout the text). For the molluscs, for example, Brown's (1994) comprehensive account of African freshwater gastropods was used to systematically search each species' information to establish whether or not it is known to inhabit temporary wetland environments. Similarly, for odonates, which have several species checklist publications covering the various sub-regions of southern Africa (Martens et al., 2003; Kipping, 2010; Samways \& Simaika, 2016), it was assessed whether the habitat preferences for the various species have been noted or not, and this information was used to construct a list of temporary wetland-dependent species.

\section{Major invertebrate groups}

\section{Porifera}

Sponges occur in permanent and temporary freshwater systems worldwide, both lotic and lentic (Manconi \& Pronzato, 2008). In southern Africa there are two known families, Spongillidae (five genera, seven species) and Potamolepidae (two genera, species information unavailable, Heeg, 2002a). There appears to be a low richness of sponge taxa in southern African freshwater environments compared to other regions (Manconi \& Pronzato, 2008) but, as with many of the lesser-known phyla, additional collecting effort is likely to reveal more species (Heeg, 2002a). Ephydatia fluviatilis (Linneaus, 1758) of the Spongillidae is the only known species that has often been recorded from temporary wetlands in the region, usually found on the stems of emergent macrophytes. This species appears to be distributed throughout South Africa (SA) and Namibia (Heeg, 2002a). Sponges generally survive 
114 drought periods through formation of gemmules, which are internal buds composed of

115 amoebocytes surrounded by an external protective coat comprising collagen layers embedded

116 with spicules (for review, see Frost, 1991).

\section{Cnidaria}

118 Hydra (class Hydrozoa) is the best-known cnidarian taxon in freshwater wetlands, and is

119 particularly abundant in temporary lentic ponds, where it is represented by solitary polyps

120 (Williams, 2006). In the region, out of the five species of Hydrozoa recorded, only

121 Limnocnida tanganjicae (Günther, 1893) is recognised as indigenous to Africa, the rest being

122 cosmopolitan species (Rayner et al., 2002). An invasive freshwater jellyfish, Craspedacusta

123 sowerbyi (Lankester, 1880), has been recorded in large numbers of man-made reservoirs

124 (Rayner et al., 2002). Hydras are capable of both asexual and sexual reproduction and are

125 known to survive in desiccated wetlands via the latter technique, whereby fertilized eggs are

126 surrounded by a thecal coat that is resistant to external desiccation and extreme changes in

127 environmental conditions in general (Williams, 2006).

128 Platyhelminthes (flatworms)

129 'Turbellarians' are common and widespread in southern African temporary wetlands, yet no

130 taxonomic key exists for species or even genera in the region (Appleton, 2002a). Young

131 (1976) recorded 80 valid species of freshwater turbellarians across Africa, but little work has

132 been done since to describe African taxa. Artois et al. (2004) described one new genus and

133 four new species of flatworm from ephemeral rock pools in Botswana. Intensive ecological

134 studies of temporary rock pool invertebrate communities in south-eastern Botswana

135 (Brendonck et al., 2002) found that turbellarians (particularly Mesostoma spp.) are key

136 predators of anostracan (fairy shrimp) egg banks in these systems, seriously affecting

137 anostracan population sizes (De Roeck et al., 2005). Mesostoma species have even been

138 recorded preying on adult Branchipodopsis shrimp in these pools (Brendonck et al., 2000b).

139 Curtis (1991) reported that only one species of freshwater turbellarian, Mesostoma brincki

140 Marcus 1970, had been positively identified from Namibia. In a comprehensive global

141 collation of turbellarian species with Gondwanan affinities, Noreña et al. (2003) listed six

142 freshwater turbellarians (Xenostenostomum microstomoides Reisinger, 1976; Prorhynchus

143 brincki Marcus, 1955; Bothrioplana semperi Braun, 1881; Mesostoma brincki; M. ewerum

144 Du Bois-Reymond Marcus 1951; Phaenocora foliacea (Böhmig, 1914)) from the region, but 
145 did not indicate how many of these occur in temporary wetlands. Houben et al. (2014)

146 reported $P$. foliacea from a temporary pond in Hluhluwe Game Reserve, SA. Tubellarians

147 can cope with the periodic drying up of temporary wetlands by producing cysts, and these can

148 come out of dormancy after 5-7 minutes of inundation (Van Steenkiste et al., 2010).

149 The other major platyhelminth groups with notable freshwater representatives are the 150 trematodes and cestodes, both of which are parasitic. There is no existing taxonomic key for 151 African trematodes and they are poorly known. Appleton (2002a) treats them according to 152 groups (types) based on morphology of the cercariae. The obvious exception to an otherwise 153 poorly-known fauna is the genus Schistosoma, which has seven species implicated in human 154 or bovine bilharzia infection and that uses Biomphalaria or Bulinus gastropod snails as 155 intermediate hosts (see 'Molluscs' below for further review of this topic). False tapeworms 156 (subclass Cotyloda) constitute the group of cestodes that can be found in freshwater 157 environments, and in the region are a common parasite of the platanna frog Xenopus laevis 158 (Daudin, 1802), but their free-living larval stages are microscopic and are never seen unless 159 specifically sought (Appleton, 2002a).

Gastrotricha

161 Gastrotrichs have been recorded from temporary wetlands worldwide, but very little

162 ecological or taxonomic information is available on these organisms in freshwater 163 environments of southern Africa (Williams, 2006). In the review of Heeg (2002b), not a 164 single species description existed for the region. The genera that have been recorded so far in 165 the region are cosmopolitan, being found particularly in Europe but also elsewhere (Heeg, 166 2002b). One recent exception is the new planktonic gastrotrich species, Kijanebalola 167 devestiva Todaro, Perissinotto and Bownes, 2013, described from a shallow pond on the 168 shores of iSimangaliso Wetland Park (KwaZulu-Natal, SA). However, despite the pond being 169 small, it appears to be permanently inundated (Todaro et al., 2013). Nevertheless, gastrotrichs 170 are well adapted to life in temporary wetlands through their production of dormant eggs

171 (Ricci \& Balsamo, 2000).

\section{Bryozoa}

173 Bryozoans have been noted as relatively common in freshwater environments in southern 174 Africa (Heeg, 2002c; de Moor \& Day, 2013), but remain largely uncollected and unstudied in 175 the region. Heeg (2002c) comments that the bryozoan fauna of Africa appears to contain 
mostly cosmopolitan species, but lists only four species as recorded from the region (Plumatella emarginata (Allman, 1844), P. repens (Linnaeus, 1758), Lophopodella capensis (Sollas, 1908) and Hyalinella punctata (Hancook, 1850)). It is highly likely that bryozoans inhabit temporary wetlands across large areas of the southern African region, given that they are well adapted to survive desiccation. Bryozoans germinate by producing desiccationresistant statoblasts that have hooks for clinging to large mobile animals such as waterfowl and are thus able to disperse passively over wide geographical areas (Bilton et al., 2001).

\section{Nematoda}

Nematodes are a highly diverse group worldwide (conservatively estimated at one million species, Abebe et al., 2008) and there are approximately 150 known species of freshwater nematodes in southern Africa, of which most are likely to be capable of surviving dry periods in moist soil (Heyns, 2002). Thirty-four of the 150 species listed by Heyns (2002) have been recorded in semi-aquatic environments and are capable of surviving near-terrestrial conditions, for example in moist soil during the dry phase of a temporary wetland.

Nematodes have commonly been recorded elsewhere as able to enter a quiescent phase without water loss in response to drying in temporary ponds (Womersley \& Ching, 1989; Wharton, 2004; Abebe et al., 2006) and thus are not expected to be limited by extreme environments in southern African temporary wetlands.

\section{Nematomorpha}

Information on the genera and species of the parasite phylum Nematomorpha (horsehair worms) in southern African water bodies is extremely sparse, but the few records that do exist suggest a wide distribution (Rayner \& Appleton, 2002). Corrêa (1951) reported two species of Prostoma as widespread in SA. In a review of known African species, SchmidtRhaesa \& Perissinotto (2016) reported a further six species from SA belonging to the genera Chordodes, Paragordius and Beatogordius. They also described a previously unconfirmed species (Chordodes ferox Camerano, 1897) collected from a live praying mantid floating in a river in the Eastern Cape province, SA. Nine species recorded by Corrêa (1951) and SchmidtRhaesa \& Perissinotto (2016) appear to be all that is known taxonomically of the fauna from the southern African region to date. Nematomorph larvae are dependent on an aquatic medium, where they generally penetrate the bodies of arthropods (particularly orthopterans) and spend the vast majority of their lives growing into large adult worms inside the host 
207 body. Thus, nematomorphs possess traits that pre-adapt them to life in temporary wetlands

208 (Williams, 2006) and it is likely that they inhabit such environments in southern Africa.

Microscopic animals belonging to the phylum Rotifera (commonly called 'wheel animals')

211 are found in a wide variety of freshwater habitats from large lakes to damp moss and are well

212 adapted to life in temporary wetlands. Rotifers have two major means of dealing with

213 desiccation. Bdelloid rotifers are able to slowly dry out and then return to activity when they

214 are rehydrated, a process known as cryptobiosis (Brain, 2002). Monogonant rotifers instead

215 survive as desiccation-tolerant resting eggs (Ricci \& Balsamo, 2000). Both desiccated

216 bdelloids and monogonant eggs are carried by wind and for this reason freshwater rotifers are

217 mostly cosmopolitan, being able to flourish wherever suitable conditions are encountered

218 (Brain, 2002). According to Dumont (1983), African rotifers are particularly cosmopolitan,

219 although no comprehensive species list exists. Brain (2002) provided a list and an

220 identification key for the 47 genera of freshwater rotifers known from southern Africa (8

221 digononts and 39 monogononts), but it is not known how many of these taxa are found in

222 temporary wetland environments. Anusa et al. (2012) reported eight rotifer species

223 (belonging to the genera Asplanchna, Brachionus, Conochilus, Epiphanes, Lepadella,

224 Rotaria and Synchaeta) as common inhabitants across a range of hydroperiods in temporary

225 rock pools in northern Zimbabwe. They found that rotifers were more abundant in pools with

226 longer hydroperiods, but were able to withstand the ephemerality of the shallow short-lived

227 pools. Dalu et al. (2016) recorded five rotifer species belonging to four genera (Brachionus,

228 Euchlanis, Filinia, Pompholyx) in an ephemeral pond in the Eastern Cape. However, more

229 species are expected to be found with more studies currently underway. Riato et al. (2014)

230 compared the zooplankton communities of temporary and permanent depression wetlands in

231 the Mpumalanga Highveld, SA, and found that Platyias quadricornis (Ehrenberg, 1832) only

232 occurred in the temporary wetlands. All nine species reported from the studies of Anusa et al.

233 (2012) and Riato et al. (2014) are widespread and all occur on other continents, thus

234 providing some preliminary indication that the temporary wetland rotifers in the region

235 comprise largely cosmopolitan species. 
237 Phylum Tardigrada ('waterbears') are tiny coelomate animals (50 $\mu \mathrm{m}$ to $1.2 \mathrm{~mm}$ in length) represented by approximately 900 species worldwide, of which only 62 species (representing

23913 genera) are truly aquatic (Garey et al., 2008). Very little is known about the aquatic

240 tardigrades in the region and there has been no definitive study on the group. They are not

241 commonly encountered by freshwater ecologists and are easily overlooked due to their small

242 size (Rayner, 2002). No taxonomic or ecological information on the aquatic tardigrades of

243 southern Africa is available. There are however a number of studies on the terrestrial and

244 semi-terrestrial tardigrade fauna of mosses, lichens and leaf litter habitats in the region (for

245 reviews see Meyer \& Hinton, 2009; Zawierucha et al., 2012). Despite the lack of studies, it is

246 strongly suspected that tardigrades inhabit southern African temporary wetlands, given their

247 exceptional adaptations to desiccation and physico-chemical extremes (reviewed by

248 Williams, 2006; Møbjerg et al., 2011).

Tardigrades are able to spend long periods in a desiccated cryptobiotic state, during which time they are unique among metazoans in their ability to withstand extreme physico-chemical fluctuations, tolerating laboratory immersion in liquid helium at $-272^{\circ} \mathrm{C}$ and temperatures as high as $340^{\circ} \mathrm{C}$ (Williams, 2006). During cryptobiosis, tardigrades are also easily dispersed by wind, as are their eggs. Once their environment is re-flooded with water they rehydrate and become active (Williams, 2006). Incredibly, tardigrades can survive for up to 70 years in the cryptobiotic state (Rayner, 2002). Life spans are more commonly less than one year however (Rayner, 2002).

\section{Annelida}

Annelid worms found in temporary wetlands in the region include earthworms (subclass Oligochaeta) and leeches (subclass Hirudinea). Although sabellid polychaetes (class Polychaeta) have been recorded elsewhere in temporary wetlands (Yozzo \& Diaz, 1999), they have not been reported in southern African. Ceratonereis keiskama Day, 1953 appears to be the only polychaete worm recorded in entirely freshwater environments in SA, where it has been recorded from permanent freshwater lakes that are estuarine relicts, being particularly abundant in Lake Sibaya in KwaZulu-Natal (Day \& Day, 2002). aquatic, of which approximately 1100 are found in freshwater environments (Martin et al., 
2008). About 50 microdrile and 20 megadrile taxa have been recorded from southern Africa

(van Hoven \& Day, 2002). Whilst most of the microdrile species are cosmopolitan, the megadriles are mostly African endemics (van Hoven \& Day, 2002). None of the taxonomic works specifically report on which oligochaete taxa are found in southern African temporary wetlands, but the megadrile earthworm Lumbriculus variegatus (Müller, 1774) (cosmopolitan species) and microdriles belonging to Nais (Naididae) have been reported in faunal lists from ecological studies of temporary wetlands in the region (e.g. Bird \& Day, 2016). Oligochaete specimens from southern African wetland studies are most commonly reported at the ordinal level as 'Oligochaeta' (e.g. Anusa et al., 2012; Ferreira et al., 2012). Oligochaetes can survive desiccation in temporary wetland environments by forming dehydration-resistant cysts, empirically documented for lumbriculids (Anlauf, 1990) and naidids (Montalto \& Marchese, 2005).

\section{Leeches are found in most freshwater habitats, although they are sparse in fast-flowing} water or wetlands that are highly ephemeral (Oosthuizen \& Siddall, 2002). Leeches are, however, well adapted to live in temporary waterbodies, mostly due to their ability to disperse via mobile vertebrates such as waterfowl (Davies et al., 1982; Williams, 2006) or attached to large invertebrates (Oosthuizen \& Siddall, 2002). Some leeches are capable of surviving droughts as adults in mucus-lined cysts (Williams, 2006). The excellent dispersal ability of leeches results in their distributions in temporary wetlands in other regions of the world being well known (Williams, 2006). There are approximately 50 species of leeches in southern Africa (Oosthuizen \& Siddall, 2002), but it is unknown how many can tolerate living in temporary wetlands. Bird \& Day (2016) reported two species, the African leech Helobdella conifera (Moore, 1933) and the globally widespread H. stagnalis (Linnaeus, 1758) from temporary depression wetlands in Cape Town, SA. Oosthuizen \& Siddall (2002) have recorded Placobdelloides multistriata (Jahansson, 1909) from temporary wetlands throughout southern Africa (the species is distributed across Africa), although they remark that the leeches usually enter small temporary pools inadvertently while attached to water scorpions and other hemipterans as transport hosts. All three of the above-mentioned species occurring in temporary wetlands thus have wide geographic distributions.

\section{Mollusca}

Approximately 111 species of gastropod and 26 bivalves have been reported from southern Africa, which includes 10 alien gastropod species (Appleton, 2002b). The region has very 
low freshwater molluscan endemicity at about 12.3\% (Appleton, 2002b). According to

300 Brown's (1994) habitat records, the following species are frequently found in temporary wetlands: Pila occidentalis (Mousson, 1887); Lanistes ovum Troschel, 1845; Tomichia ventricosa (Reeve, 1842); Ceratophallus natalensis (Krauss, 1848); Lymnaea natalensis Krauss, 1848; L. columella (introduced from North America, now widespread in Africa); Physa acuta Draparnaud, 1805 (introduced from Europe, now widespread in Africa); Biomphalaria pfeifferi (Krauss, 1848); Bulinus globosus (Morelet, 1866) B. forskalii (Ehrenberg, 1831); B. reticulatus (Mandahl-Barth, 1954); B. tropicus (Krauss, 1848); B. scalaris (Dunker, 1845); and Aplexa marmorata (Guilding, 1828). Aplexa marmorata is an invasive species from South America, which has recently been recorded from temporary wetlands as far south as Cape Town by Mlambo et al. (2011). seasonal pools throughout Africa (Brown, 1994). Although several studies have recorded Ferrissia at the generic level in South African temporary wetlands (Mlambo et al., 2011; Bird et al., 2013; Bird \& Day, 2016), species level information is unavailable. Members of this genus are able to partly close the shell using a septum, which facilitates aestivation during the dry phase of a temporary wetland (Brown, 1994).

Of the African gastropods, the genus Bulinus excels in temporary wetland environments

317 (Vera et al., 1995). For example, B. depressus and B. scalaris were the species most

318 commonly found in isolated seasonal pools in Moremi Game Reserve, Botswana (Appleton et al., 2003). Similarly, B. forskalii was the only mollusc collected together with branchiopods in rain pools on the Makathini Flats (Hamer, 1989). The success of Bulinus snails can, at least in part, be put down to their ability to aestivate for up to six months and then exploit nutrient-rich temporary water bodies upon re-inundation by breeding rapidly ( $\mathrm{r}-$ selected growth) during the short breeding season (Brown, 1994).

Bulinus and Biomphalaria are the two best-studied gastropod genera in southern Africa because they are the aquatic intermediate hosts of human and bovine schistosomiasis (Rubaba et al., 2016). Although species of Biomphalaria commonly occur in temporary habitats in the Neotropical region (Paraense, 1996), this is rare for the African counterparts. Biomphalaria species in the Neotropics often have lamellae in their shells' apertures that are thought to play a role in tolerating desiccation. In a southern African context, only one specimen of $B$. pfeifferi is known to have apertural lamellae (Appleton CC, personal communication). 

inhabit temporary wetlands (Williams, 2006). The three genera of Sphaeriidae (Sphaerium,

333 Pisidium and Eupera) present in southern Africa are in need of revision (Appleton, 2002b)

334 and information on which sphaeriid species are known to inhabit temporary wetlands in the region appears to be lacking. Sphaeriids have been shown elsewhere to deal with desiccation by burrowing into the substrates of drying wetlands (McKee \& Mackie, 1980). Most species require some residual moisture in the substrate to survive the dry season (at least 15\% moisture for two Canadian sphaeriid species, McKee \& Mackie, 1980) and thus are not likely to be encountered in highly ephemeral wetlands. Sphaeriids have effective dispersal mechanisms (e.g. clipping onto the limbs of mobile invertebrates and waterfowl) and are selffertilizing hermaphrodites, adaptations that further allow them to exploit temporary environments (Williams, 2006).

\section{Crustaceans: Malacostraca}

344 Most freshwater-dwelling members of the class Malacostraca (i.e. Amphipoda, Isopoda and

345 Decapoda) lack physical adaptations for diapause or dispersal. Thus, they are not commonly associated with temporary wetlands but, due mostly to behavioural adaptations, certain species are able to persist in temporary waters (Williams, 2006). Amphipods appear to be very scarce in southern African temporary wetlands and virtually no records exist of their occurrence in these systems. Mlambo et al. (2011) and Bird \& Day (2016) both recorded populations of the Gondwanan relictual species Paramelita capensis (Barnard 1916) and $P$. pinnicornis Stewart and Griffiths 1992 in small temporary wetlands of the Kenilworth Racecourse Conservation Area in Cape Town. However, studies of how these amphipods survive the summer dry phase have not been undertaken. A study of the North American amphipod Crangonyx pseudogracilis Bousfield, 1958 provides evidence that this epigean species is able to inhabit parts of the water table during the dry phase of a temporary wetland and this mechanism explains both its ability to persist and its ubiquity across a network of nearby wetlands (Harris et al., 2002). The authors suggest that such subterranean explorations by epigean amphipods may be a key mechanism for amphipod survival in temporary wetlands in other parts of the world. Another interesting behavioural adaptation in amphipods is reported from a congeneric North American amphipod, C. antennatus Packard, 1881, which survives the desiccated phase of mud-bottom pools by digging a burrow into the mud 
that is then blocked off from the outside with an air bubble (Holsinger \& Dickson, 1977). The burrow itself remains hydrated and provides a temporary aquatic refuge until the pool refills.

True crabs (Brachyura) also deal with desiccation by burrowing into the substrate. At least four southern African species (namely Potamonautes lividus Gouws, Stewart and Reavell, 2001, P. flavusjo Daniels, Phiri and Bayliss, 2014, P. isimangaliso Peer \& Gouws, 2015, and P. calcaratus (Gordon, 1929)) exhibit a vaulted carapace, which is an adaptation to a semiterrestrial lifestyle away from permanent waters (Daniels et al., 2014). All of these species may appear superficially similar morphologically, but phylogenetically they are very distinct (Daniels et al., 2014; Peer et al., 2015). From north-eastern KwaZulu-Natal, Potamonautes lividus and $P$. isimangaliso are documented to live in close association with highly ephemeral depression wetlands (Peer et al., 2015). These crabs occupy 0.3-0.5 m deep burrows within the wetland substrate that remain moist throughout the dry season. Brachyurans associated with temporary waterbodies worldwide have often also evolved physiological air-breathing adaptations such as the ability to efficiently draw oxygen from moist air within burrows (Cumberlidge, 2009), and this appears to be the case for P. isimangaliso (Peer et al., 2015). Similarly, $P$. calcaratus displays the same ecological habits as $P$. isimangaliso, surviving in burrows around ephemeral pools in the KNP (Daniels et al., 2014). Another congeneric, $P$. flavusjo, burrows into peat soils in Highveld wetlands in Mpumalanga province where it remains submerged in water by following the vertical movement of the water table (Daniels et al., 2014).

The only freshwater isopods known to inhabit temporary wetlands in the region belong to the genus Mesamphisopus (Gouws et al., 2005). Barnard (1926) observed that Mesamphisopus abbreviatus (Barnard, 1927) burrows into muddy substrata in small mountain streams that seasonally run dry. It aestivates in these burrows by lowering its metabolism and breathing the moist air in the burrows, in a similar fashion to P. isimangaliso. Mesamphisopus has been reported from temporary depression wetlands in the Western Cape province (Mlambo et al., 2011; Bird et al., 2013). prawns or shrimps in the freshwater temporary wetlands of southern Africa (indigenous freshwater crayfish do not occur in Africa). 
393 The class Branchiopoda, as a matter of convenience rather than taxonomic distinction, are

394 usually treated as two groups: the large branchiopods (fairy shrimps, tadpole shrimps and 395 clam shrimps) and the cladocerans (water fleas). Following suit, we address the cladocerans 396 in a separate section together with their microcrustacean counterparts, the ostracods and 397 copepods.

398 The large branchiopods are the enigmatic flagship invertebrates of temporary wetlands worldwide (Brendonck et al., 2008). They are specialists of lentic environments that incorporate a dry phase, although in some cases they do occur in fishless semi-permanent waterbodies (Ferreira et al., 2011). Their adaptations to ephemeral waterbodies have led to their prevalence in arid and semi-arid regions, where such waterbodies predominate. This is no exception in the largely semi-arid subcontinent of southern Africa, where they are widespread and diverse. The large branchiopod fauna is well studied in the region compared to most of the aquatic invertebrate groups so far covered in this review and to date approximately 66 species have been recorded (Tuytens et al., 2015).

Large branchiopods generally exhibit a lifestyle of rapid growth and maturation, followed by the production of drought-resistant eggs that can lie dormant in dry sediment under harsh conditions for decades and perhaps even centuries (Brendonck et al., 2008). Generally speaking, populations adopt a 'bet-hedging' strategy in that not all eggs hatch with the first onset of inundation, but rather some eggs remain dormant and only hatch after subsequent inundations so as to ensure survival of the population in a wetland that dries before a cohort reaches maturity (Simovich \& Hathaway, 1997; Brendonck et al., 1998; Brendonck et al.,

414 2008). Eggs are generally dispersed passively to other waterbodies via wind (Brendonck \& 415 Riddoch, 1999; Vanschoenwinkel et al., 2009), ingestion by predators, which transport the 416 eggs in their gut (Rogers, 2014, 2015), or by attachment to mobile fauna (Vanschoenwinkel 417 et al., 2011). More specific aspects of the adaptations of large branchiopods to temporary 418 wetlands environments, including their biology and reproduction, are covered elsewhere (for reviews see Belk et al., 1991; Brendonck, 1996; Brendonck et al., 1998; Dumont \& Negrea, 2002; Rogers, 2009). 
conditions, human impacts, management and conservation) have received considerable research attention due largely to a series of studies of rock pools in the eastern Free State province (Vanschoenwinkel et al., 2007; Vanschoenwinkel et al., 2009; Vanschoenwinkel et al., 2010a; Vanschoenwinkel et al., 2010b; Pinceel et al., 2013; Vanschoenwinkel et al., 2013; Tuytens et al., 2014) and south-eastern Botswana (Brendonck et al., 1998; Brendonck et al., 2000a; Brendonck et al., 2000b; De Roeck et al., 2005; Jocqué et al., 2006; Jocqué et al., 2010). Recently, the large branchiopod fauna of soft-bottomed wetlands and rock pools have received ecological attention in Zimbabwe (Nhiwatiwa et al., 2011; Anusa et al., 2012; Nhiwatiwa et al., 2014; Tuytens et al., 2015; Nhiwatiwa et al., 2017a; Nhiwatiwa \& Dalu, 2017; Nhiwatiwa et al., 2017b) and the Western Cape province (De Roeck et al., 2007; De Roeck et al., 2010; Mlambo et al., 2011). A scattering of studies exists from various other localities, including Namibia (Day, 1990; Curtis, 1991), Botswana (Brendonck \& Riddoch, 1997), the Drakensberg (Hamer \& Martens, 1998), and soft-bottomed wetlands in the Free State (Seaman et al., 1991; Meintjes, 1996), Mpumalanga (Ferreira et al., 2011, 2012), NorthWest (de Necker et al., 2016), Northern Cape (Hamer \& Rayner, 1996) and KwaZulu-Natal (Hamer \& Appleton, 1991) provinces of SA. As far as we are aware, no ecological studies on large branchiopods have been recorded from Mozambique.

The best-known of the large branchiopods is the order Anostraca (fairy shrimps). Early taxonomic descriptions in the southern African region were pioneered by G.O. Sars and E. Daday, but largest contribution to anostracans systematics was made by K.H. Barnard of the South African Museum during the 1930s-1940s. During the 1990s, various workers updated diversity and distribution data for the anostraca of the region. Hamer et al. (1994) and Brendonck \& Coomans (1994) reviewed the Streptocephalidae south of the Zambezi and Kunene rivers and reported a total of 16 species. Brendonck (1995) added a new genus and species Rhinobranchipus martensi Brendonck, 1995 (Branchipodidae) to the southern African list of anostraca, which was collected from a shallow depression wetland in the Thomas Baines Nature Reserve in the Eastern Cape province. Hamer (1999) provided a taxonomic key for identification of the 46 southern African species of anostracans (six genera and four families) known at the time, all of which are known to occur in temporary freshwater wetlands with the exception of members of the genera Artemia and Parartemia, which are adapted to hypersaline salt lakes and salt pans. Nhiwatiwa et al. (2017b) recently described a new species, Stretocephalus sangoensis Nhiwatiwa, Dalu \& Brendonck, 2017 in 
cf. bidentatus, indicating that more research is still required to prove valid species status and identify more taxa.

Brendonck et al. (2000b) provided a focussed review on the genus Branchipodopsis, the members of which are shown to be specialists of transparent, very fresh $\left(<50 \mu \mathrm{S} \mathrm{cm}^{-1}\right)$ and often highly ephemeral rock pools in the region. They described Branchipodopsis species as the 'record holders' of an ephemeral lifestyle in these rock pools, where populations are able to grow to maturity within the first week after inundation. Their long-distance dispersal ability by wind appears to be rare and rather they disperse to other nearby pools via overflows. This is suggested as a potential factor behind the high levels of endemism of Branchipodopsis species within the region. Since 2000, two new anostracan species have been described from KwaZulu-Natal province belonging to the genus Metabranchipus ( $M$. rubra Rogers and Hamer, 2012 and M. prodigiosus Rogers and Hamer, 2012) of the family Branchipodidae.

Otherwise, the only recent notable taxonomic work in southern Africa concerning the anostracans is for the genus Artemia (Artemiidae, commonly known as brine shrimp). Artemia has been in a state of taxonomic confusion for quite some time (Hamer, 1999). The genus is cosmopolitan and restricted to salt lakes and salt pans with salinity levels above approximately $40 \mathrm{~g} \mathrm{~L}^{-1}$, where fish and many predatory invertebrates are absent (Kaiser et al., 2006). In southern Africa, populations seem to be a mix of bisexual and parthenogenetic forms (Kaiser et al., 2006). The sexually reproducing species cannot be distinguished by gross morphological characters and require genetic analyses to separate species. Since such work had not been conducted in the region until recently, members of the genus have been referred to at generic level. However, Baxevanis et al. (2014) attempted the genetic identification of Artemia species in SA. Phylogenetic and network analyses revealed that three out of the seven studied populations belong to the invasive A. franciscana Kellog, 1906, while four belong to A. salina (Linnaeus, 1758). This is the first confirmed report of the invasive $A$. franciscana in the region and highlights concern regarding its invasive ability, as demonstrated by its complete replacement of the native A. salina population at the Veldrift Saltworks on the west coast of SA. Given that Baxevanis et al. (2014) only investigated seven populations, the taxonomic status of Artemia populations in the broader southern African region stills requires investigation. 
Brendonck \& Riddoch (1997) conducted a comprehensive survey of the anostracan fauna of Botswana, sampling from approximately 200 localities around the country, collecting both live specimens and mud samples containing eggs. They reported 14 anostracan species, with only one (Branchipodopsis kalaharensis Daday, 1910) being endemic to Botswana. They attribute the higher species richness (33) and endemicity (64\%) in SA to greater habitable surface area, topographic and environmental heterogeneity, and research effort. Hamer \&

493 Brendonck (1997) expanded on the work of Brendonck \& Riddoch (1997) by establishing a species-level checklist of the anostracan fauna for the whole region, providing a detailed distribution of each species. They divided the anostracan fauna into ten biogeographic categories, shaped largely by climatic factors: (i) widespread species occurring across southern Africa; (ii) eastern escarpment species occurring at high altitude within the Drakensberg; (iii) arid south-west species occurring in the arid and semi-arid regions of Namibia and the Karoo; (iv) tropical/subtropical species occurring on the low-lying eastern margin of southern Africa; (v) southern savannah species; (vi) Highveld species occurring in summer rainfall areas on the plateau at altitudes of $1000-1500 \mathrm{~m}$; (vii) Cape east coast species occurring in winter-rainfall areas of the southern and south-eastern Cape margins; (viii) Cape west coast species occurring from Cape Town northwards along the west coast; (ix) Eastern Cape inland species (two species), of which Streptocephalus dregei Sars, 1899 occurs in the more arid lowland areas towards the south, whilst S. spinicaudatus Hamer and Appleton, 1993 occurs more northwards at higher altitude and with higher annual rainfall; and (x) Zimbabwean species that have been collected mainly from Zimbabwe and also Zambia, but not further south.

The order Notostraca (tadpole shrimps) are branchiopod crustaceans that are known from as far back as the Triassic Period, earning them the status of 'living fossils' (Fryer, 1988;

511 Vanschoenwinkel et al., 2012), although recently this concept for the group has been 512 challenged (Mathers et al., 2013). Rayner (1999) provides an overview of the morphology, 513 habitat preferences, feeding, reproduction and identification of southern African notostracans. 514 Two species of Triops have been recorded from southern Africa, T. granarius (Lucas, 1864) 515 and T. cancriformis (Bosc, 1801), although the latter is rare and has only been recorded from 516 Ovamboland (northern Namibia) and the Kalahari (Hamer \& Rayner, 1995). T. granarius is common and widespread in the drier areas of southern Africa $(<500 \mathrm{~mm}$ mean annual

518 rainfall), preferring muddy temporary pools seldom exceeding one hectare in size (for more detailed distribution records see Hamer \& Rayner, 1995). Triops taxonomy in southern Africa 
520 (and worldwide for that matter) is not without controversy. For instance, Korn \&

521 Hundsdoerfer (2006) used ribosomal DNA markers to investigate genetic distinctiveness of T. granarius populations from Tunisia, Namibia and Japan, and their results strongly suggest

523 that the three populations belong to different, possibly cryptic species. Thus, further

524 molecular phylogenetic work on African Triops populations is required to more clearly

525 resolve cryptic species complexes.

526 The third major group of large branchiopods frequenting temporary wetlands are the clam 527 shrimps, although the colloquial term is used here solely for descriptive convenience. The 528 clam shrimps consist of the order Laevicaudata (smooth clam shrimp, one family with three genera and 39 species) and, in the order Diplostraca, two suborders: Spinicaudata and

530 Cyclestherida, with approximately 116 known species (four families and 16 genera) 531 worldwide (Brendonck et al., 2008; Rogers et al., 2012). All three groups are primitive and

532 known as far back as the Devonian (Gueriau et al., 2016). Despite being abundant and 533 widespread in arid-zone temporary wetlands of the region (and worldwide), the taxonomy of 534 the clam shrimps has been poorly studied. The systematics has been problematic and 535 complicated by morphological plasticity in the fine details, despite generally uniform gross 536 morphology (Rogers et al., 2012). The difficulty in finding diagnostic morphological 537 characters appears to be a prime reason why virtually no taxonomists have tackled the 538 systematics of southern African clam shrimps since the studies of G.O. Sars, R. Gurney, G.S. 539 Brady, E. Daday, K.H. Barnard and V. Brehm.

540 Brendonck (1999) provides a taxonomic key to distinguish the southern African species of 541 clam shrimps, although only genus-level distinction is provided in some cases (e.g. Cyzicus 542 Audouin, 1837), due to difficult taxonomy. Brendonck (1999) also provides distribution 543 records for the 18 species known at the time of his assessment. The only notable taxonomic 544 work that includes southern African clam shrimps in recent times is a revision of the 545 worldwide genera of the Limnadiidae (Spinicaudata) by Rogers et al. (2012), who combined 546 morphological and molecular information to show the presence of eight well-defined genera, 547 including two new genera (Afrolimnadia Rogers, Rabet \& Weeks, 2012 and Calalimnadia 548 Rogers, Rabet \& Weeks, 2012). South African material was used for the description of 549 Afrolimnadia alluaudi (Daday, 1926). Afrolimnadia was subsequently renamed 550 Gondwanalimnadia Rogers, Rabet \& Weeks, 2016 because it is a junior homonym of 
551 Afrolimnadia Tasch, 1987, an fossil genus of spinicaudatan clam shrimps (Rogers et al.

552 2016).

554 Southern Africa has a diverse ostracod fauna. Martens (2001) reported about 155 species (ca. 55 genera) belonging to the class Ostracoda from the region, but remarked that dozens of new species await description. Since this publication, several new species and genera have also been added to the regional list (Martens, 2003, 2007; Jocqué et al., 2010), including the rediscovery of two species of giant ostracod (Liocypris grandis Sars, 1924 and Afrocypris barnardi Sars, 1924) that were thought to be extinct (Martens, 2003; Matzke-Karasz \& Martens, 2007), both from temporary wetland habitats. The most striking feature of the ostracod fauna of the region is the high endemicity of the Western and Eastern Cape provinces, which although possessing few endemic genera, harbour many endemic species (de Moor \& Day, 2013). The northern and central parts of Namibia and Botswana and the southern part of Zimbabwe form another belt of high endemism, with generic endemism in these areas being comparable to the exceptionally rich and endemic ostracod fauna of Lake Tanganyika (Jocqué et al., 2010). The ostracod fauna of southern Africa exhibits its highest endemism and diversity in temporary wetland environments where few cosmopolitan species occur (Martens, 2001). Ostracods are mostly benthic scavengers (although some forms are pelagic) and play an important role in temporary wetland ecosystems as detritivores (Martens, 2001). The success of ostracods in temporary wetlands is largely attributed to their production of highly desiccation-resistant eggs, but also their ability to reproduce parthenogenetically and the ease with which their eggs are passively dispersed to other waterbodies via wind dispersal or attached to other animals (for review see Horne \& Martens, 1998).

Martens (2001) provides a taxonomic key for the genera (and species for some recentlyrevised genera) of southern African freshwater ostracods, many of which are found in temporary wetland environments. Following this reference, the genera that have been unequivocally recorded from temporary wetlands are: Cypricercus, Eundacypris,

579 Gomphocythere, Globocypris, Korannacythere, Leucocythere, Megalocypris,

580 Ovambocythere, Physocypria, Pseudocypris, Ramotha, Sarscypridopsis, Sclerocypris, 581 Zonocypris. Jocqué et al. (2006) reported Potamocypris and Strandesia from temporary rock 582 pools in Botswana, while Amphibolocypris (A. arida and A. exigua) were recorded from 
583

temporay rock pools in Botswana and a temporary soft-bottomed wetland in KNP, respectively (Jocqué et al., 2010).

In the Western Cape province, Martens (2007) recorded the genus Mnementh from temporary wetlands; and Martens et al. (1996) reported Zonocypris cordata Sars, 1924 and Physocypria capensis Sars, 1896, which are both found in temporary and permanent wetlands. Additionally, Bird \& Day (2016) recorded the following genera Chrissia; Sarscypridopsis; and Gomphocythere from temporary depression wetlands within the Kenilworth Racecourse Conservation Area, Cape Town. This also included the following species: Cypretta turgida Sars, 1896, Cypricercus episphaena (Müller, 1908), Cypridopsis vidua (Müller, 1908), Paracypretta acanthifera Sars, 1924, P. capensis, Ramotha capensis (Müller, 1908), and Zonocypris cordata Sars, 1924.

Reviewing the ostracod fauna of KwaZulu-Natal, Martens et al. (1998) report that most of the diversity in lowland temporary wetlands of the province is in the genera Heterocypris and Cypricercus, but diversity and endemicity in these habitats is generally low. The higher altitude temporary rock pools of the Drakensberg have high diversity and endemicity in the genera Sarscypridopsis and Heterocypris. However, most notable of the Drakensberg pools is the diversity within the family Limnocytheridae that is unmatched anywhere else in the world.

\section{Crustaceans: Copepoda}

Copepods are one of the most diverse crustacean groups, including over 14,000 known species of both free-living and symbiotic forms. Most free-living copepods are marine, but approximately 2,800 species have colonized a wide variety of freshwater habitats (Boxshall $\&$ Defaye, 2008). Copepods in freshwaters represent a pivotal component of the food webs as part of the zooplankton and benthic/littoral communities worldwide. Up to 20 genera and 51 species of freshwater copepods have been recorded from the region (Rayner, 2001). Most of the information available for the region concerns the calanoid copepods (order Calanoida) and there has been virtually no recent taxonomic research on the cyclopoids or harpacticoids. Among the calanoids, only members of the exclusively freshwater family Diaptomidae have been recorded in the region (Rayner \& Heeg, 1994). The subfamily Diaptominae, containing about 410 species, is represented in the region by the genera Tropodiaptomus and Thermodiaptomus, both of which occur in more permanent waters and are not considered 
614 further here. The diaptomid subfamily Paradiaptominae currently consists of 25 species

615 (Suárez-Morales et al., 2015), most of which are endemic to Africa and adapted to life in 616 temporary wetlands (Rayner, 2001). This largely endemic group includes a genus, Lovenula,

617 that comprises extremely large individuals (de Moor \& Day, 2013). Rayner (2001) provides a

618 taxonomic key to the species of Diaptomidae in the region, along with cursory notes on the

619 cyclopoid and harpacticoid taxa that have been described or recorded from the region. The

620 following species in the subfamily Paradiaptominae have thus far been recorded from

621 temporary wetlands in the region (for distributional information, see Day, 1990; Rayner,

622 1998; Rayner, 2000, 2001; Suárez-Morales \& Rayner, 2004; Suárez-Morales et al., 2015):

623 Lovenula falcifera (Lovén 1845), L. africana (Daday, 1908), L. simplex Kiefer, 1929, L.

624 raynerae Suárez-Morales, Wasserman \& Dalu 2015, Paradiaptomus lamellatus Sars, 1895,

625 P. schultzei van Douwe, 1912, P. similis van Douwe, 1912, P. peninsularis Rayner, 1999, P.

626 hameri Rayner, 1999, Metadiaptomus capensis (Sars, 1907), M. purcelli (Sars, 1907), and M.

627 meridianus (van Douwe, 1912).

628 The cyclopoids (order Cyclopoida), on the other hand, are represented in freshwaters by

629 the widespread family Cyclopidae; in Africa this group is represented by 167 species, a figure

630 that resembles that of the Neotropical region (174 species), but is about half the number

631 found in the Palaearctic region (337 species) (Boxshall \& Defaye, 2008). In southern Africa,

632 records of cyclopids are scarce and mostly consist of cosmopolitan species. This is probably

633 the result of the $19^{\text {th }}$ Century species concepts and delimitations that were extensively used

634 and applied by European researchers who named species from different geographic regions

635 on the basis of their resemblance with European species. Revisionary studies have proved

636 that records of some of these "cosmopolitan" nominal species (i.e. Acanthocyclops vernalis

637 (Fischer, 1853) and A. robustus (Sars, 1863)) represent species complexes containing

638 undescribed taxa. The South African cyclopoid copepod fauna certainly deserves further

639 examination with recent taxonomic standards. The following cyclopoids have been recorded

640 in temporary wetlands in the region (for distributional information, see Day, 1990; Rayner,

641 2001): A. vernalis, Mesocyclops major Sars, 1927, Thermocyclops oblongatus Sars, 1927, T.

642 macracanthus Kiefer, 1929, T. schuurmanae Kiefer, 1928, Microcyclops crassipes (Sars

643 1927), M. inopinatus (Sars, 1927), Eucyclops (Afrocyclops) gibsoni (Brady, 1904), E.

644 sublaevis (Sars, 1927), E. serrulatus (Fischer, 1851), Tropocyclops prasinus (Fischer, 1860),

645 Ectocyclops phaleratus (Koch, 1838), Paracyclops poppei (Rehberg, 1880), and $P$.

646 fimbriatus (Fischer, 1853). 

moderate diversity (108 species), which is comparable to that of India and Thailand. The most diverse harpacticoid family, the Canthocamptidae is represented by only 46 species in

650 Africa, whereas more than 320 occur in the Palaearctic region (Boxshall \& Defaye, 2008).

651 Records of Harpacticoida in southern Africa are extremely scarce, let alone which taxa are 652 known from temporary waters. Nitokra dubia Sars, 1927 and Elaphoidella bidens coronata 653 Kiefer, 1934 have both been recorded from temporary wetlands of the Cape Flats near Cape 654 Town, SA (Rayner, 2001). Vanschoenwinkel et al. (2008) recorded Bryocamptus sp. from temporary rock pools of the eastern Free State province. Rayner (2001) lists Attheyella natalis Brady, 1904, A. warreni Brady, 1913, Harpacticus meridionalis Sars, 1927, Cletocamptus confluens meridionalis Kiefer, 1934 and C. trichotus Kiefer, 1934 as other harpacticoid species that occur in southern Africa, but information could not be sourced on whether these species occur in temporary wetlands.

Of the ecological work directed specifically at copepods, most has focussed on aspects related to diapause. Diapause is a stop in the ontogenetic development induced by the need of physiological adjustments in the individual; in copepods this process affects one stage only, occurs regularly and is only partially related to environmental factors. Dormancy is a reversible cessation of development clearly related to environmental changes and involves different stages (depending on the species and environmental scenario) including eggs, nauplii, copepodites and adults (Dahms, 1995). Eggs are the most common dormant stage among diaptomids, and in cyclopoids dormancy is frequently related to copepodites $\mathrm{C} 4$ or C5 (Suárez-Morales et al., 2015). Diapause occurs under drying or unfavourable environmental conditions and is a dominant feature of the life cycle of many copepod species and a major factor in their successful colonisation of temporary wetland habitats worldwide (Dahms, 1995; Williams, 2006). In temporary ponds, cyclopine cyclopoids can emerge from diapause within a single day of the appearance of water (Reid \& Williamson, 2010). Unlike ostracods, copepods generally reproduce sexually, but often have very fast development times, as little as one week to reach the adult stage, depending on prevailing environmental conditions

675 (Williams, 2006). Similarly to ostracods, however, eggs are passively dispersed via wind or attached to mobile fauna (Dahms, 1995). Very little other ecological work has been directed specifically at copepods, with the exception of Wasserman et al. (2016a), Dalu et al. (2017b), 
679 ecology of the paradiaptominids L. raynerae and P. lamellatus in the Eastern Cape province 680 of SA.

682 In contrast to copepods, most of the world's over 600 species (Forró et al., 2008) of

683 Cladocera ('water fleas') occur in freshwater environments, where they often dominate the 684 lentic fauna in terms of abundance. Southern Africa harbours a mixture of Afrotropical, 685 Palaearctic, circumtropical and local endemic elements in its cladoceran fauna (Smirnov, 686 2008; Van Damme et al., 2013). The taxonomy of cladocerans in the region requires an 687 urgent overhaul, particularly the Chydoridae and the Daphniidae (Seaman et al., 1999; Van 688 Damme et al., 2013), thus an estimate of the number of species in the region is not presently available. Smirnov (2008) reported 112 cladoceran species from SA, with a wide representation of Palearctic species. Traditionally, the region was considered to possess low levels of cladoceran endemism (Frey, 1993; Korovchinsky, 2006; Smirnov, 2008), but more recently this has been attributed to the limited state of knowledge of the fauna rather than genuinely low endemism (Van Damme et al., 2013). As is the pattern for Ostracoda and

694 Copepoda, the greatest cladoceran species richness and endemicity in the region occurs in 695 temporary wetland environments, particularly montane rock pools in the east (e.g.

696 Drakensberg) and endemics of Western Cape lowland pools (Van Damme et al., 2013). The 697 families Chydoridae and Macrothricidae, the sub-genus Daphnia (Ctenodaphnia) and the genera Ceriodaphnia and Moina are common inhabitants of temporary wetlands in the region

699 (Seaman et al., 1999). A literature search of taxonomic and ecological records of cladocerans

700 from temporary wetlands in the region was attempted, but given the urgent need of taxonomic revision of species in this region (Van Damme et al., 2013), it was later abandoned.

Survival strategies of cladocerans in temporary wetlands are broadly similar to those of the other microcrustaceans, with highly desiccation-resistant eggs being produced as water levels draw down (Vandekerkhove et al., 2005). Cladocerans favour parthenogenetic (asexual) cloning during favourable times when the wetland is inundated and males are rare for much of the hydroperiod (Williams, 2006). Males appear more frequently towards the end of the hydroperiod and sexual reproduction prevails as water disappears from the wetland. Whilst parthenogenetic cloning produces soft eggs for rapid development, sexually produced eggs are encased in a hardened ephippium and can withstand drying, freezing and passive dispersal 
711 to other waterbodies (Bilton et al., 2001; Vandekerkhove et al., 2005; Williams, 2006). As

712 has been found in many aquatic environments globally, cladocerans have also been identified

713 as important trophic components in systems of the region (Dalu et al., 2016; Wasserman et

714 al., 2016b; Dalu et al., 2017b; Dalu et al., 2017c).

\section{Hydrachnidia: Water mites}

716 Water mites (suborder Hydrachnidia) are abundant and ubiquitous in temporary wetlands and 717 over 6000 species have been described worldwide from freshwater environments, including

718160 species from southern Africa (Di Sabatino et al., 2008). Since then, more species have

719 been added to the southern African records for Torrenticolidae (Goldschmidt \& Smit, 2009),

720 Hygrobatidae (Pešić et al., 2013), Mideopsidae (Pešić et al., 2013), Arrenuridae (Smit, 2012) and Hydryphantidae (Gerecke, 2004). Jansen van Rensburg (1976) provided a taxonomic key to identify the 22 water mite families from the region (updated by Jansen van Rensburg \& Day, 2002). Throughout the key, and indeed also for more recent species-level accounts (see above), no mention is made in the habitat descriptions for each taxon as to the preference for temporary versus permanent water bodies. Hence, we are unable to provide further information from the taxonomic literature regarding those taxa specifically known to inhabit temporary wetlands in the region. The following taxa have been recorded from temporary wetlands in the south-western Cape Mediterranean-climate region of SA (records from Mlambo et al., 2011 unless otherwise specified), with the help of Dr R. Gerecke, Tübingen, Germany, and Dr E. Ueckerman, ARC, Pretoria: Arrenurus spp. (Arrenuridae), Eylais spp. (Eylaidae), Hydrachna fissigera Koenike, 1898, Hydryphantes parmulatus Koenike, 1912, Diplodontus schaubi (Koenike, 1893), Mamersa testudinata Koenike, 1898, Limnochares crinita Koenicke, 1898, Piona sp. (Pionidae), and Neumania spp. (Unionicolidae). In addition, hygrophilous representatives of several terrestrial mite taxa were reported by Bird et al. (2013) from the cohorts Gamasina (Macrocheles sp., Macrochelidae), Astigmatina (Oribatida), and Parasitengona (Trombidiidae).

The great diversity of water mites in temporary habitats is remarkable, given that most do not possess the typical adaptations of temporary wetland invertebrates (either diapause of eggs/adults or active dispersal as adults) (Bohonak et al., 2004). Instead, the radiation of water mites in temporary wetlands has been facilitated by parasitic larvae that, once hatched from eggs laid within a waterbody, parasitize adult insects and are thus dispersed to other waterbodies (Bilton et al., 2001; Bohonak et al., 2004). Parasitism is obligate in all species 
studied so far that colonize astatic water bodies, and mite larvae die if they fail to penetrate an insect host (Bohonak et al., 2004). However, not all water mites survive the dry phase via parasitism, and certain taxa (e.g. some members of the Hydryphantidae) are capable of surviving dry phases as deutonymphs or adults that enter an inactive state in microhabitats with persistent moisture, such as moist mud or damp crevices in logs (Wiggins et al., 1980;

748 Bohonak et al., 2004).

\section{Insecta: Ephemeroptera (mayflies)}

750

The order Ephemeroptera have the distinction of being the most ancient lineage of extant winged insects, dating back to the late Carboniferous or early Permian periods (Brittain \& Sartori, 2003; Barber-James et al., 2008). Despite over 3500 species worldwide and 435 species from the Afrotropical region (Sartori \& Barber-James, 2018), most mayfly diversity is represented in running waters and this ancient group is relatively depauperate in lentic environments (Newell \& Hossack, 2009). A baetid species, Cloeodes hydation McCafferty \& Lugo-Ortiz, 1995, from temporary wetlands (rock pools, ephemeral pools and springs) of the Pantanal wetland system was the first mayfly species to be experimentally shown to withstand repeated drying conditions of up to nine hours at a time (Nolte et al., 1996). On the contrary, a known inhabitant of intermittent waters, Daleatidium spp. (Leptophlebiidae), from New Zealand dies only after three hours of drying exposure (Robinson \& Buser, 2007). However, Nolte et al. (1996) made a distinction between $C$. hydation and the chironomid Polypedilum vanderplanki Hinton, 1951, calling it drying-tolerant as opposed to dryingresistant, which the latter is. Although the genus Cloeodes occurs in the region, a similar characteristic of drying-tolerance has not been demonstrated, and it has also not been reported from temporary wetlands. In southern Africa, only members of the genera Cloeon Leach, 1815 and Procloeon Bengtsson, 1915 (Baetidae) are known from truly lentic waterbodies such as dams and wetlands and appear to be capable of reaching high abundance in temporary waterbodies (Barber-James \& Lugo-Ortiz, 2003). Similar results have been reported in Irish turloughs (Reynolds, 2000).

Although the aquatic nymphal phase of these baetid mayflies is rather delicate and desiccation-intolerant, populations persist in temporary wetlands due to the nymphs being extremely fast-growing (reaching maturity in 2-3 weeks) and the adults apparently producing desiccation-resistant eggs (Williams, 2006). Dispersal is via short-lived winged adults or via passive dispersal of eggs (Bilton et al., 2001; Williams, 2006). Barber-James \& Lugo-Ortiz 
775

776

777

778

779

780

781

782

783

784

785

786

787

788

789

790

791

792

793

794

795

796

797

798

799

800

801

802

803

804

805

(2003) list 22 Afrotropical species of Cloeon (nine from SA) and three species of Procloeon (one from SA). It is not yet known which of these species inhabit temporary wetland environments, which reflects the desperate need for more species-level studies of mayflies in Africa (Barber-James \& Gattolliat, 2012). Cloeon is widespread in the region and has been recorded from temporary wetlands throughout the region, including the Western Cape (Mlambo et al., 2011; Bird et al., 2013) and Mpumalanga (Foster et al., 2015) provinces of SA, Namibia (Day, 1990), Zimbabwe (Chakona et al., 2008) and Botswana (Jocqué et al., 2006).

Gillies (1990) reported the unusual habitat of the baetid Acanthiops erepens (Gillies, 1990), which occurs in Tanzania on rock in semi-permanent vertical trickles and in the splash zone next to small cascades. The nymphs cling to moss growing on the rock face that is kept moist by spray from the adjacent waterfall, and if disturbed they plummet into the waterfall pool below.

\section{Insecta: Odonata}

The order Odonata, comprising some 5,680 species worldwide (Kalkman et al., 2008), is divided into the suborders Zygoptera (damselflies) and Epiprocta, which is further divided into the infraorders Anisoptera (dragonflies) and Aniszygoptera (Asian species only) (Rehn, 2003). As with the Ephemeroptera, the odonates are an ancient order, dating back well into the Permian (Kalkman et al., 2008). The Odonata are relatively well studied, especially in the Afrotropical region where their diversity is depauperate compared to other tropical regions (Dijkstra, 2003) and thus their taxonomy is relatively well known in comparison to other freshwater invertebrate groups (but still not without some confusion, see Dijkstra, 2003). That said, Dijkstra et al. (2015) recently described a further 60 new African species as adults, from regions north of the area under review in this paper. Therefore, if brightly coloured, charismatic creatures such as adult Odonata are still incompletely known, how much less do we yet know about the more obscure freshwater invertebrates, especially those inhabiting temporary waterbodies in Africa.

802 Unlike many of the African freshwater invertebrates, IUCN Red List information has been compiled for many of the southern African odonate species, with most of the threatened species being habitat specialists occurring in highland areas of the Western and Eastern Cape provinces (Samways, 2004), many frequenting temporary water bodies, but most as 
806

807

808

809

810

811

812

813

814

815

816

817

818

819

820

821

822

823

824

825

826

827

828

829

830

831

832

833

834

835

836

837

838

opportunistic visitors rather than being dependent upon these habitats. Odonate species exploiting temporary habitats depend on dispersal for survival and tend to have large home ranges and are habitat generalists, being tolerant of ecological change (Clausnitzer et al., 2012). Thus, temporary wetland species are generally not threatened. In southern African arid regions, no desert endemics are known and most of the widespread desert-inhabiting species are powerful fliers belonging to the Anisoptera that are not restricted to deserts, being more common in savannah wetlands (Suhling et al., 2003). The 889 known odonate species of the Afrotropical region (Kalkman et al., 2008) all have aquatic larvae, which are not capable of withstanding desiccation themselves (for a rare exception from Brazil, see Van Damme \& Dumont, 1999). Odonate populations are however, able to persist in temporary habitats through production of drought-resistant eggs combined with fast-growing larvae, multivoltine life cycles and strong active dispersal of adults (for more detailed reviews of odonate adaptations to temporary habitats, see Johansson \& Suhling, 2004; Suhling et al., 2005; De Block et al., 2008; Hassall \& Thompson, 2008). Timing of hatching may also be important. Schiel \& Buchwald (2015) showed that for 15 species of odonates across three genera (Lestes - Lestidae, Aeshna - Aeshnidae and Sympetrum - Libellulidae), species inhabiting only temporary ponds hatched significantly earlier in the year than congeners inhabiting a combination of permanent and temporary ponds. Despite the harsh environmental conditions often presented in temporary waterbodies, a major reward for exploiting such habitats is often the reduced predation pressure on larvae (lack of fish for instance) allowing them to forage actively for food, whereas in permanent waters larvae generally need to remain concealed and rely on ambush predation (Hassall \& Thompson, 2008).

Several checklists are available covering various sub-regions of southern Africa, from which habitat preferences of the various species can be discerned (if such information is available at all). Martens et al. (2003) listed 102 odonate species from Namibia. They listed the following taxa as facultative inhabitants of temporary wetlands: Lestes pallidus Rambur, 1842, Ischnura senegalensis (Rambur, 1842), Anax ephippiger (Burmeister, 1839), Pantala flavescens (Fabricius, 1798), and Sympetrum fonscolombii (Selys, 1840). Suhling et al. (2003), in their investigation of desert-adapted odonates, listed the following species from ephemeral pools in the Namib desert of Namibia: Africallagma glaucum (Burmeister, 1839), Ischnura senegalensis (Rambur, 1842), Anax ephippiger, A. imperator Leach, 1815, Paragomphus genei (Selys, 1841), Crocothemis erythraea (Brullé, 1832), Orthetrum chrysostigma (Burmeister, 1839), Palpopleura lucia (Drury, 1773), P. flavescens, S. 
839 fonscolombii, Trithemis annulata (Palisot de Beauvois, 1807) and T. kirbyi ardens

840 (Gerstäcker, 1891). Mlambo et al. (2011) recorded the anisopteran genera Anax (Aeshnidae)

841 and Trithemis (Libellulidae) and the zygopteran genera Africallagma, Ischnura and

842 Pseudagrion (all Coenagrionidae) from temporary wetlands of the Western Cape. Jocqué et

843 al. (2006) reported the larvae of $P$. flavescens as top predators in temporary rock pools of

844 south-eastern Botswana. Simaika et al. (2016) investigated the benefits of artificial ponds as

845 biodiversity refugia for Western Cape dragonflies and listed the following taxa from a

846 temporary pond: A. imperator, C. erythraea, I. senagalensis, Orthetrum chrysostigma

847 (Burmeister, 1839), O. trinacria (Selys, 1841) and Trithemis arteriosa (Burmeister, 1839).

848 Samways (1999) noted L. pallidus as a frequent inhabitant of temporary wetlands in SA,

849 while Clark \& Samways (1996) recorded Palpopleura deceptor (Calvert, 1899), P. jucunda

850 Rambur, 1842, P. lucia, Bradinopyga cornuta Ris, 1911, T. kirbyi ardens and P. flavescens

851 from ephemeral rock pools in KNP. Interestingly, larvae of the libellulid Hemistigma

852 albipunctum (Rambur, 1842), which inhabits marshes and swamps, can remain alive in the

853 mud as these habitats dry out, surviving with minimal water and emerging as an adult before

854 the local area completely dries out (Samways, 2008).

855

Kipping (2010) provided a checklist of the odonates of Botswana and noted that most of

856 the country's odonates are widespread African savannah species that, although having a

857 preference for more stable habitats, are able to disperse over wide distances and breed in temporary waterbodies in arid areas such as the Kalahari Desert. Suhling et al. (2009) reported that true obligate migrant species of the arid Kalahari region include $P$. flavescens,

860 S. fonscolombii and A. ephippiger. Kipping (2010) recorded the following species as 861 facultative inhabitants of temporary wetlands of Botswana: Lestes dissimulans Fraser, 1955,

862 L. pallidus, L. pinheyi Fraser, 1955, A. glaucum, Azuragrion nigridorsum (Selys, 1876),

863 Ceriagrion suave Ris, 1921, I. senegalensis, A. ephippiger, A. tristis Hagen, 1867,

864 Brachythemis leucosticta (Burmeister, 1839), B. cornuta, Diplacodes luminans (Karsch, 865 1893), Orthetrum brachiale (Palisot de Beauvois, 1817), O. caffrum caffrum (Burmeister, 866 1839), O. chrysostigma chrysostigma (Burmeister, 1839), O. trinacria, P. deceptor, $P$. 867 flavescens, Rhyothemis semihyalina (Desjardins, 1832), S. fonscolombii, Tramea basilaris 868 (Palisot de Beauvois, 1807), T. kirby ardens and Urothemis assignata (Selys, 1872). For 869 more detailed information on the distribution, habitat and Red List status of these species, the 870 reader is referred to Kipping (2010) and Samways \& Simaika (2016). 
In some odonate species there are temporal changes in geographic range in accordance with the wet and dry cycles of the El Niño Southern Oscillation. An extreme case was for Aciagrion dondoense Dijkstra, 2007, which was not known in SA prior to the year 2000 when it appeared in great numbers on the KwaZulu-Natal coast, having come down the coast with flooding farther north. A few years later it was gone from the country with the dry phase appearing (Samways, 2010). Several South African species are adapted to these cycles, with species like Orthetrum robustum Balinsky, 1965 retreating from temporary pools in the dry phase to permanent lakes, to return later to the temporary pools in the wet cycle (Samways, 2008). One last factor to consider is that rivers that stop flowing and have only pools ('kuile') in the dry season. Such pools in these rivers may attract species temporarily until the river flows again. There may even be a succession of species as the pools gradually dry out, with Pseudagrion commoniae (Förster, 1902) and P. salisburyense Ris, 1921 being the last to survive before the pools finally dry out (Samways, 2008).

\section{Insecta: Hemiptera}

The hemimetabolous insect order Hemiptera is usually considered to contain four suborders: Sternorrhyncha (aphids, whiteflies, and scale insects); Auchenorrhyncha (cicadas and hoppers); Coleorrhyncha (moss bugs); and Heteroptera (true bugs) (Capinera, 2008; Forero, 2008). It comprises some 82,000 described species, and possibly almost 200,000 species in total worldwide. The bugs associated with water all belong to the Heteroptera, particularly the semi-aquatic Gerromorpha and the predominantly aquatic Nepomorpha. Gerromorphs have hydrophobic tarsi and gracile bodies that allow them to stand on the water surface supported by the surface tension of the meniscus, while nepomorphs generally crawl or swim underwater and typically have reduced antennae and ocelli. The Nepomorpha have a fossil record dating back about 250 million years (Grimaldi \& Engel, 2005).

Most species have winged adults that disperse well and can therefore colonise temporary wetlands quickly. The nepomorph families all breathe air through plastrons or respiratory tubes, and the gerromorph families are epipleustonic, living just above the water surface rather than in the water, so dissolved oxygen does not limit the potential of a water body for colonisation by water bugs. The species in most families are generalist predators, and can therefore inhabit a wide variety of waters with flow rates that are slow or absent. Many gerromorphs associate with floating or emergent vegetation that helps them to avoid predators and being washed away in flowing waters (Reavell, 2003). Immature nymphs have 
903 biologies similar to their adults, but cannot fly, so they complete their development only in

904

905

906

907

908

909

910

911

912

913

914

915

916

917

918

919

920

921

922

923

924

925

926

927

928

929

930

931

932

933

934 temporary wetlands that take more than (generally) four to ten weeks to dry up. Adults of some species of gerromorph may be winged or apterous (regulated by temperature and photoperiod); when apterous adults inhabit a temporary wetland, they indicate that at least one generation has completed its life cycle in the wetland. The high mobility and broader habitat preferences of most aquatic bugs means that populations of temporary wetland species are generally not threatened (Collinson et al., 1995).

The morphology, taxonomy and general ecology of the southern African water bug fauna was summarised by Reavell (2003), who stated that little work had been done on the fauna of the region, and that it needed urgent taxonomic revision. Reavell (2003) provided a key to the families of aquatic Hemiptera in the region, and a list of the known genera, but keys to the genera and species are still lacking. Ecological and life history studies of temporary wetland water bugs in the region include Hutchinson (1933), Hynes (1955), Weir (1966), Tawfik (1969), Boettger (1974), Mlambo et al. (2011), Ferreira et al. (2012), Bird et al. (2013) and Nhiwatiwa et al. (2017a). Hemiptera from six families constituted an average of $14 \%$ of the individual invertebrates surveyed in a large number of temporary waters in the Western Cape (Mlambo et al., 2011), and Hemiptera were co-dominant with Coleoptera (beetles) in nine temporary pans in Mpumalanga (Ferreira et al., 2012). The dominant families are usually Corixidae and Notonectidae. The water bugs tend to be associated with warmer, alkaline water in temporary pans (Ferreira et al., 2012), and larger-bodied species are more common in the absence of fishes in ephemeral pans (Nhiwatiwa et al., 2017a; Nhiwatiwa et al., $2017 b$ ). However, because of their high vagility and relatively broad habitat tolerances, water bugs may be poor indicators of anthropogenic effects on temporary wetlands in SA (cf. Bird et al., 2013), an effect that can be compounded by artefacts of the sampling method (de Klerk $\&$ Wepener, 2013). Their instantaneous diversity may also be related to the stage of the wetland's hydroperiod (Lahr et al., 1999; Dalu et al., 2017b; Dalu et al., 2017c), since older wetlands have had more time to become colonised and develop prey populations, thus obscuring the effects of human activities.

\section{Insecta: Trichoptera}

Trichoptera are holometabolous insects, mostly with an aquatic larval and a terrestrial adult phase. They have been recorded worldwide with the exception of some oceanic islands and the polar regions (de Moor \& Scott, 2003). The Trichoptera World Checklist (Morse, 2011) 
935 lists 14548 species of 616 genera in 49 families recorded globally thus far. Of these, 1193 936 species $(8.2 \%)$ in 83 genera from 21 families are known to occur in southern Africa (Tobias $937 \&$ Tobias, 2008). Recently, some species were collected in temporary wetlands, despite the 938 earlier assertion of Scott (1970) that Trichoptera do not inhabit temporary lentic waters of the 939 region: Oxyethria velocipes (Barnard, 1934) (Jones, 2002; Day et al., 2010) and Athripsodes 940 sp. (Bird, 2012), both from the Western Cape province; and Ecnomus thomasseti Mosely, 941 1932, Oecetis sp. and Oxyethira sp. from Mpumalanga province (Ferreira et al., 2012).

942 Trichoptera found in temporary waters show several adaptations to this habitat in different 943 life stages, but little is known about this in southern Africa as research has mainly been 944 conducted on species from other regions, discussed below. Larvae use silk to construct 945 transportable or fixed cases from material readily available, such as sand, small stones, sticks, 946 leaves and algae. The ability to build cases has allowed trichopteran larvae to adapt to a wide 947 range of environmental conditions: spring sources, mountain streams, splash zones of 948 waterfalls, large rivers, lakes and temporary wetlands (de Moor \& Scott, 2003). Many species 949 are represented in cooler and faster-moving waters as dissolved oxygen is a limiting factor for 950 habitat colonisation (de Moor \& Scott, 2003).

951 Trichopteran larvae are apneustic, which means that they lack spiracles; they take up 952 dissolved oxygen through the thin abdominal membrane by direct diffusion. Their abdominal 953 surfaces are often expanded with tubular or branched gills that increase the surface area of the 954 abdominal membrane. To ensure sufficient uptake of dissolved oxygen, larvae can create a 955 current through their cases by abdominal undulation. This aids gas exchange when oxygen 956 concentrations are low, as is the case in temporary wetlands (Williams, 1987; de Moor \& 957 Scott, 2003).

958 As water levels decrease during drying, faunal density increases and cases offer a 959 protective body covering and camouflage to protect larvae from predation. A combination of 960 case material (mineral rather than organic), shape (short, wide case with "hedgehog" structure 961 rather than long tubular cases or flat purses) and defensive behaviour (retreating deep into the 962 case and remaining motionless) are adaptive strategies employed by Limnephilus externus 963 Hagen, 1861 against predation by diving beetle larvae (Dytiscus sp.) (Wissinger et al., 2006). 964 Another species, L. picturatus McLachlan, 1875, evades predation of pupae by burrowing 965 into soft substrates to pupate, whereas larvae of Asynarchus nigriculus (Limnephilidae) 966 (Banks, 1908) build stronger mineral cases prior to pupation. Furthermore, both species have 
967 faster developmental times, which reduce temporal overlap with predators (Wissinger et al., 968 2003). Pupae can develop while the water column has dried up and the soil is still moist 969 (Wiggins, 1973). The case material is important with regard to pond-drying. Larvae of $L$. 970 coenosus Curtis, 1834 construct cases using organic material whereas L. vittatus (Fabricius, 971 1798) larvae use mineral material. Organic material has been shown to retain moisture better 972 than mineral material, preventing drying of larvae (Zamora-Muñoz \& Svensson, 1996).

973 Cases also protect caddisfly larvae from inter- and intraspecific aggression as water levels 974 decrease (Wissinger et al., 2004b). Aggressive behaviour includes fighting (foreleg wrestling, 975 biting, case shaking) and mobbing of individuals (involving 5-10 larvae) which often results 976 in death and cannibalism of conspecifics (Lund et al., 2016). Wissinger et al. (2004b) have 977 shown that cases reduced or prevented cannibalism significantly among larvae of $A$.

978 nigriculus. Cases also reduced vulnerability of three Limnephilus species (L. externus, L. 979 picturatus, L. secludens Banks, 1914) to intraguild predation by A. nigriculus (Banks, 1908).

980 Aggression among A. nigriculus in mesocosm experiments was higher in high-density 981 treatment and even higher in the absence of dietary protein supplement (Lund et al., 2016). 982 Although aggressive behaviour has trade-offs, such as injury and subsequently becoming a 983 secondary victim, cannibalism provides an important protein- or lipid-rich dietary supplement 984 that offers advantages later in the life-cycle.

Dietary experiments on L. coenotus and L. vittatus supplementing detritus diet with 986 protein have shown that larger larvae survive drying better as they contain more water compared to smaller ones (Zamora-Muñoz \& Svensson, 1996). Furthermore, body mass of adult L. externus significantly increased when ambient food treatment was supplemented with a protein-rich supplement (Jannot et al., 2008). Larval diet can have a significant long-term effect on adult fitness (Jannot, 2009) as female body size is correlated with fecundity and male body size with mating success (Wissinger et al., 2004a).

Adults of L. externus, L. picturatus and A. nigriculus emerge prior to pond-drying and 993 females enter an ovarian diapause after mating (Wissinger et al., 2003). Summer diapause is 994 an important adaptation to survive dry periods (Wiggins, 1973; Wiggins et al., 1980), which 995 also protects eggs from predation, drying and freezing (Wissinger et al., 2003). Oviposition in 996 temporary pools usually occurs above or near water, not directly in water as is normal for 997 most trichopteran species (Wiggins, 1973). Eggs are deposited in a gelatinous egg-matrix, 998 which is highly resistant to extremes like desiccation and freezing (Wiggins, 1973). Eggs are 
999 deposited under rocks and logs, where larvae hatch and develop further within a gelatinous

1000 mass until re-wetting occurs (Wissinger et al., 2003). Lectrides varians Mosely, 1953 show a

1001 bimodal response - some larvae become active with the first onset of re-wetting or re-

1002 immersion whereas others remain aestivating and only become active when surface water

1003 levels are more stable. Although this adaptation ensures population survival, it is at the cost

1004 of larval survivorship (Wickson et al., 2012). Larvae enter the temporary ponds with, for

1005 example, melt water, develop further and pupate prior to pond-drying (Wissinger et al.,

1006 2003).

1007 Insecta: Diptera

1008 Virtually all African temporary waters support the larvae of at least one species of fly, and

1009 flies boast of a large array of adaptive mechanisms for this variable environment (McLachlan

1010 \& Ladle, 2001). In the region, the families Chironomidae, Ceratopogonidae and Culicidae

1011 commonly occur even in the Kalahari and Namib deserts, where rain may fall only at

1012 intervals of several years. Although dipterans are ubiquitous in these systems, very few

1013 species are able to survive desiccation (Williams, 2006). Unlike many branchiopod

1014 crustaceans, which withstand dry periods as desiccation-resistant cysts, most flies that occur

1015 in temporary waters survive the dry period as adults or, in the case of some culicids, as larvae

1016 in perennial water bodies. Hinton (1953) indicated that some African Stratiomyidae can

1017 withstand desiccation, though this is not recorded in southern Africa.

1018 Chironomids mostly survive dry periods as adults. Frouz et al. (2003) reviewed the

1019 strategies employed by chironomids to survive the variable environment of temporary

1020 wetlands. Given that larvae of several species are found in hyper-arid conditions in the

1021 Namib Desert, where pools may not form for 5 to10 years at a stretch, the question yet to be

1022 answered is, "How are the adults able to survive the dry years in these environments?" A few

1023 other species survive for some time in stout pupal cocoons during dry periods (Armitage,

1024 1995), but presumably these periods are relatively short. When it comes to survival under

1025 harsh conditions, larvae of the 'sleeping chironomid', Polypedilum vanderplanki Hinton,

1026 1951, hold the record. The species breeds in small unshaded rock pools in Central and West

1027 Africa. Larvae can undergo up to 17 years of desiccation and, when wetted, will 'wake up'

1028 and behave normally, feeding and growing until the next time they are desiccated. Hinton

1029 (1960) performed various experiments on these remarkable organisms, showing that they can

1030 withstand temperatures between $-270^{\circ} \mathrm{C}$ and $+102^{\circ} \mathrm{C}$ and can survive through a 
1031

1032

1033

1034

1035

1036

1037

1038

1039

1040

1041

1042

1043

1044

1045

1046

1047

1048

1049

1050

1051

1052

1053

1054

1055

1056

1057

1058

1059

1060

1061

1062

wetting/drying cycle at least ten times. An additional species of 'sleeping chironomid', $P$. ovahimba Cranston, 2014, has been recently described from rock pools of the Waterberg Plateau, Namibia (Cranston, 2014).

Other chironomids, such as Chironomus pulcher Wiedemann, 1830, also breed in rain pools on rocks throughout much of Africa and have rapid life cycles. Larvae of the chironomid subfamily Podonominae (Archaeochlus sp. and Afrochlus harrisoni Freeman, 1964) are found in temporary trickles over rocks and boulders in the Drakensberg, on granite inselbergs near Harare, and in Namibia (Harrison, 2002). Similarly, Harrisonina petricola Freeman, 1956 was originally found breeding in the thin film of water running over stones in an ephemeral stream in the Olifants River Valley. It is not known how these survive dry periods. Rock pools in Africa are dominated by dipteran larvae (up to 300000 per pool), which are often the only macroinvertebrate inhabitants. If the pools are very short-lived (1-2 days), the only inhabitants are larvae of $P$. vanderplanki. Pools lasting several weeks often support Chironomus imicola Kieffer, 1913, which has little tolerance of desiccation, but is able to complete its life cycle in 10-12 days (McLachlan \& Cantrell, 1980).

Larvae of a few ceratopogonid species are found in extremely arid regions (de Meillon \& Wirth, 2002) and yet they seem not to be particularly adapted to withstanding desiccation. There are no African examples. Larvae of Culicoides sonorensis Wirth \& Jones, 1957 from the Sonoran Desert in North America, for instance, are able to survive drying, but only for a day or two (McDermott \& Mullens, 2014). Pools lasting several days often contain larvae of the ceratopogonid Dasyhelea thompsoni de Meillon, 1936 that burrow into mud at the bottom of the pond when water evaporates (McLachlan \& Cantrell, 1980). Similarly, Dodson (1987) found that Dasyhelea subletti Wirth, 1987 was the most common taxon in short-lived ephemeral rock pools in the Moab desert, USA.

Numerous species of culicid are associated with temporary waters in Africa (Coetzee, 2002), and many of them are vectors of parasites causing disease in humans and other vertebrates. Several of the vectors prefer to breed in very small containers such as old tyres, pots, and in footprints, or in phytotelmata: pools of water held by plants, for instance in the axils of leaves. Aedes aegypti (Linnaeus, 1762) is the vector of yellow fever. While the disease does not occur in southern Africa, Ae. aegypti does. It breeds in tiny containers, and the eggs can withstand desiccation for years (Coetzee, 2002). Farnesi et al. (2015), comparing the degree of resistance to desiccation of eggs of three species of mosquito, have shown that 
eggs of Ae. Aegypti can survive in a dry form for months, those of Anopheles aquasalis

1064 Curry, 1932 for a day, and of Culex quinquefasciatus Say, 1823 for a few hours, these times

1065

1066

1067

1068

1069

1070

1071

1072

1073

1074

1075

1076

1077

1078

1079

1080

1081

1082

1083

1084

1085

1086

1087

1088

1089

1090

1091

1092

1093

relating to the thickness of the egg shell. The members of 'floodwater Aedes', which can be vectors of Rift Valley Fever, such as Ae. (Neomelaniconion) mcintoshi Huang, 1985, Ae. (Neo.) circumluteolus (Theobald, 1908), Aedes (Neo.) luridus Mcintosh, 1971, Aedes (Neo.) lineatopennis (Ludlow, 1905), Aedes (Ochlerotatus) caballus (Theobald, 1912) and Aedes (Och.) juppi Mcintosh, 1973, aestivate as eggs for up to 20 months (Jupp et al., 1980).

Several members of the genus Anopheles are vectors of malarial parasites. Although some anophelines prefer to oviposit in temporary waters, neither the eggs nor the larvae are resistant to desiccation. First-instar larvae of An. gambiae s.l. are said to be amphibious (Miller et al., 2007), in that they can survive in the film of water on the surface of mud. Both An. gambiae s.s. and An. arabiensis Patton, 1905 (two South African vectors of malaria) prefer sunny temporary pools and puddles, the major adaptation to this biotope being very rapid larval development. Mosquitoes appear to overwinter as larvae in permanent waters (Appleton et al., 1995).

A few species of other dipteran families are known to occur in temporary waters in southern Africa, but very little is known about their systematics or their biology. We hypothesise that those occurring in the very arid western areas, such as the Namib Desert, have some specific adaptations that allow them to persist in areas where rain pools are the only surface freshwaters and these may fill only every few years.

\section{Insecta: Coleoptera}

Worldwide, beetles are one of the most abundant and speciose macroinvertebrate groups in inland waters, occurring across the entire hydrological spectrum, from the smallest puddles and phytotelmata, to large lakes and rivers. Water beetles are not a single taxonomic group, and instead result from around 15-20 transitions between land and water during the evolutionary history of the Coleoptera (Jäch \& Balke, 2008; Mckenna et al., 2015; Short, 2018). Beetles are diverse and frequent inhabitants of temporary waterbodies, where carnivorous taxa such as diving beetles (Dytiscidae) are often the top predators. Temporary pool inhabitants are typically a mix of specialist and more generalist species, some of which may only occur there temporarily as adults. In many cases, specialising in temporary pools may have arisen as a life-history strategy to evade fish predation, and in the northern 
hemisphere some taxa characteristic of temporary ponds (e.g. Agabus labiatus (Brahm, 1790)) are also found in permanent, acidic, fish-free sites (Foster et al., 2016). Unlike most freshwater insect groups, the majority of water beetles are aquatic as both larvae and adults,

1097 but in many cases, the precise ecology of these life-history stages differs to some extent.

1098 Some beetles utilise temporary waters primarily for reproduction, with adults occupying 1099 different habitats. In the Mediterranean, Acilius duvergeri Gobert, 1874 for example,

1100 breeding occurs in temporary lagoons, where larvae feed on microcrustacea in open water (a 1101 strategy which would make them vulnerable to fish predation in permanent waters), whilst adults occupy permanent ponds during summer drought (Dettner, 1982).

Temporary pond water beetles have a variety of strategies to survive during the dry phase, reflecting the diverse origins of aquatic beetles themselves, and the repeated evolution of temporary water specialists from within these aquatic lineages. Temporary water species may have shorter larval duration compared to their permanent water relatives, allowing development to be completed during relatively short hydroperiods (e.g. Peters, 1972), and a range of approaches exists to surviving dry phases, including migration to permanent waters or adult/egg diapause in situ (e.g. Nilsson, 1986a, b, c). The most temporary of water bodies appear to be devoid of breeding water beetles, suggesting that the extent to which larval duration can be truncated may be limited. In addition, beetle larvae do not seem to have the same resistance to desiccation as many temporary-water Crustacea (see above), but do have the advantage that adults of most species can fly between habitats (e.g. Bilton et al., 2001).

1114 In southern Africa, members of a number of beetle families can be found in temporary 1115 water bodies, although there are no formal publications dealing with their biology and 1116 ecology. As a consequence, the following information is based on Bilton (pers. obs.), unless 1117 otherwise stated. The faunas of vegetated temporary pools and rock pools appear to be quite 1118 distinct, and in addition brackish water bodies have their own specialised beetle fauna.

1119 Haliplidae are relatively rare in southern Africa, and members of Haliplus and Peltodytes are 1120 mostly found in larger, more permanent waters. The rare Cape endemic, Algophilus

1121 lathridioides Zimmermann, 1924 is poorly known ecologically, but appears to be a specialist 1122 of slightly mineralised waters. The only recent record of this beetle is from the Berg River 1123 floodplain close to Hopefield, where it occurs abundantly in slightly brackish temporary 1124 flood pools in grassland. Algophilus is wingless, and is likely to be dispersed during floods, having been found in floodwater along the Berg River in spring. 
1126 Whereas the Noteridae are largely permanent water inhabitants, a number of Dytiscidae 1127 are temporary pond specialists, and others are found there occasionally or temporarily as 1128 adults. Canthyporus species occur across a spectrum of freshwater habitats, including 1129 seepages, streams and ponds, both permanent and temporary (Biström \& Nilsson, 2006;

1130 Bilton et al., 2015). This genus is particularly diverse in the Cape, where most of its species 1131 are endemic. Many of the species in this genus, including C. aenigmaticus Biström \& Nilsson 11322006 and C. lateralis (Boheman, 1848), are characteristic inhabitants of small mountain rock 1133 pools, where both adults and presumed larvae can be found. Some inhabited pools form parts 1134 of temporary stream/seepage systems during periods of high rainfall, whereas others 1135 constitute completely isolated basins. Cape vernal pools are also inhabited by Canthyporus, 1136 including the relatively generalist $C$. hottentottus (Gemminger \& Harold, 1868) and $C$. 1137 petulans Guignot, 1951, as well as C. exilis (Boheman, 1848), a species otherwise found in 1138 temporary seeps and marshes. Besides the widespread genus Hyphydrus, the South African 1139 Hyphydrini includes five endemic genera (see Ribera \& Balke, 2007), three of which occur in 1140 temporary ponds. Darwinhydrus solidus Sharp is found from the Cederberg to Port Elizabeth, 1141 in both permanent and temporary waters, but is most frequent in densely vegetated Cape 1142 vernal pools. Primospes suturalis Sharp, 1882 is largely restricted to the far southwest of the 1143 Western Cape, and occurs in temporary pools and rivers, and two Hydropeplus species are 1144 inhabitants of both stream pools and temporary lentic pools, both vegetated and rock pools. 1145 Species of the genus Rhantus can also be found in vegetated temporary ponds, as both adults 1146 and presumed larvae, as can the phylogenetically isolated Cape endemic Caperhantus 1147 cicurius (Fabricius, 1787) (Bilton, 2017). The Critically Endangered Cape endemic 1148 Capelatus prykei Turner \& Bilton 2015 has been found in vernal pools on the Cape Flats 1149 (Bilton et al., 2015).

1150 To date, only a single species of the largely Holarctic genus Helophorus has been reported 1151 from southern Africa. Helophorus aethiops Balfour-Browne, 1954 is found throughout much 1152 of the winter rainfall zone, and is common in a variety of temporary pools, particularly 1153 shallow sites with exposed silt or sand substrates. The species-level taxonomy of southern 1154 African Hydrochus remains incompletely resolved, but a number of species are found in 1155 vegetated temporary ponds, as can many members of the Hydrophilidae, including Enochrus 1156 hartmanni Hebauer, 1998; Enochrus (Methydrus) spp.; Helochares spp; Paracymus spp; 1157 Berosus spp. and Limnoxenus sjoestedti Knisch,1924, the latter being restricted to the South 1158 African Cape (Short \& Liebherr, 2007). 
1159 The regional hydraenid beetle fauna is one of the most diverse on earth, most species in 1160 the region being Cape endemics. Here the family also attains its maximum ecological and

1161 morphological diversity, with both aquatic and (semi)terrestrial representatives (e.g. Perkins

1162 \& Balfour-Browne, 1994). Species of the genus Prosthetops, which includes some of the

1163 largest hydraenids on earth, are characteristic inhabitants of temporary rock pools, where

1164 larvae and adults can be abundant, grazing biofilms. Bilton (2013) noted that large larvae of

$1165 P$. wolfbergensis Bilton, 2013 became active underwater in previously dry rock pools one day

1166 after rains, suggesting some desiccation resistance mechanism in these insects. During dry

1167 periods, Prosthetops adults can be found in rocky streams, although this does not appear to be

1168 their breeding habitat. Temporary vegetated freshwater ponds are inhabited by a number of

1169 species of Hydraena (Hydraenopsis), Ochthebius and Parhydraena, whilst temporary saline

1170 pools are home to species of Ochthebius, including O. capicola (Péringuey, 1892), a

1171 specialist of supralittoral coastal rock pools (Sabatelli et al., 2013), a habitat independently

1172 colonised by members of this genus on a number of occasions worldwide (Sabatelli et al.,

1173 2016).

\section{Discussion}

1175 Much of southern Africa is characterised by a semi-arid or arid climate (Davis, 2011) and 1176 small temporary wetlands, though not widely acknowledged, are one of the most abundant 1177 and ubiquitous aquatic features of such landscapes (Silberbauer \& King, 1991; Brendonck \& 1178 Williams, 2000; Williams, 2006). The invertebrates found in these wetlands, whilst not 1179 widely acknowledged, constitute a significant proportion of the total aquatic biodiversity of 1180 the region. Whilst some recent research has highlighted the ecological and biodiversity 1181 importance of temporary wetland invertebrates (e.g. Spencer et al., 2002; Nicolet et al., 2004; 1182 Urban, 2004; Jeffries, 2005; Williams, 2006; Vanschoenwinkel et al., 2007; Ruhí et al., 2013; 1183 Batzer \& Boix, 2016; Kneitel, 2016; Dalu et al., 2017a), baseline biodiversity data on these 1184 faunas are often lacking. Here we present such a synthesis for southern Africa, in the hope 1185 that this will aid further ecological investigations of temporary wetlands in the region.

1186 A clear finding of this work is that, with the exception of a few groups (e.g. gastropod 1187 molluscs, odonates and certain dipteran families that act as disease vectors), we are often 1188 unable to reliably name many of the invertebrate organisms inhabiting these waterbodies. 1189 This becomes most obvious for the 'lower' invertebrate groups covered in this review, which 1190 is perhaps not surprising given their small size and the practical difficulties which may be 
1191 associated with collection and identification. For some of these groups, notably gastrotrichs,

1192 bryozoans and tardigrades, there is very little information about the freshwater species that

1193 occur throughout the region, including temporary wetlands. Although there is better

1194 information in this regard for the Northern Hemisphere, the 'lower' invertebrate phyla of

1195 freshwater environments have been relatively neglected worldwide (see Balian et al., 2008).

1196 Perhaps more surprisingly, the status quo reveals that in some cases we cannot put reliable

1197 names on species for groups represented by larger and more 'charismastic' organisms such as

1198 the 'clam shrimps' (Laevicaudata, Cyclestherida and Spinicaudata, but see Rogers et al., 2012

1199 for revision of the family Limnadiidae), ephemeropterans and many of the hemipterans from

1200 temporary freshwater wetlands of the region. Harpacticoid copepods are another example of a

1201 taxon completely unstudied in the region, even from permanent freshwater systems.

1202 To get a better hold on patterns of richness and endemism, one first needs to know what

1203 species are present in these wetland systems. A case in point is the Cladocera, which have

1204 traditionally been considered to contain few endemics in the region (Frey, 1993;

1205 Korovchinsky, 2006; Smirnov, 2008). More recent work suggests that the apparent low

1206 endemism is most likely an artefact of the limited state of knowledge of the fauna, rather than

1207 genuinely low endemism (Van Damme et al., 2013). Thus, statements on patterns of richness

1208 and endemism are of a preliminary nature at present for many of the invertebrate groups. A

1209 few such patterns are worthy of comment here. First, only for a few of the groups is evidence

1210 presented that they reach higher richness and/or endemicity in temporary wetlands than for

1211 their permanent wetland counterparts. These taxa include large branchiopods, ostracods,

1212 copepods, cladocerans, certain diperans (notably culicids) and coleopterans (some dytiscids).

1213 Thus, for the vast majority of freshwater invertebrate taxa in the region, permanent

1214 waterbodies would appear to hold a greater richness and/or endemicity than temporary ones.

1215 Despite this, temporary wetlands support unique and specialised taxa. For instance, the

1216 temporary wetland ostracod fauna of northern and central Namibia and Botswana has a

1217 generic endemicity rivalled worldwide only by East African paleolakes (Martens, 2001).

1218 Another feature of the ostracod fauna is the specific diversity in the family Lymnocytheridae

1219 for rock pools of the Drakensberg (SA), which is unmatched anywhere else in the world

1220 (Martens et al., 1998). Southern Africa is considered one of the world's hotspots of large

1221 branchiopod diversity (Tuytens et al., 2015), almost all of which is housed in temporary

1222 wetlands. When considering the region's area, the anostracan fauna is one of the richest

1223 worldwide and also has a very high endemicity ( $80 \%$ at the time of the review of Hamer \& 
1224 Brendonck, 1997). Other than for the anostracans and ostracods, further commentary on which of the major invertebrate groups covered in this review stand out globally for their richness/endemism is limited due to the taxonomic uncertainty associated with most of the groups in the region, as highlighted above.

Identifications to genus and species level of specimens mentioned in this review are mostly based on morphological characteristics (unless specifically mentioned otherwise) and accuracy greatly depends on reliable identification keys and taxonomic expertise, which is considered a scarce skill in southern Africa (Hamer, 2013). The few region-specific keys that exist are in need of updating (Barber-James \& Gattolliat, 2012). Species identification using molecular systematics has only become prominent in the region recently (da Silva \& Willows-Munro, 2016) and will greatly contribute to more accurate identification of species recorded in temporary wetlands in future.

Another general trend picked up from this review is that virtually all of the major invertebrate groups possess some sort of adaptation for survival in temporary wetlands.

1238 Although only certain taxa can truly withstand desiccation (e.g. branchiopods, ostracods and copepods), many taxa have dispersal mechanisms which allow them to leave the waterbody before it dries up (e.g. leeches, water mites and odonates), or are able to survive the drought phase as adults (e.g. dipterans). Many of the taxa inhabiting these environments are habitat generalists that may opportunistically exploit temporary waterbodies for the advantages afforded by these environments, such as reduced levels of predation and competition

1244 (although this notion is in itself controversial, see Brendonck et al., 2002). A case in point is 1245 the Odonata and Hemiptera, which are common and widespread in temporary wetlands of the region, but tend to be opportunistic colonisers of these environments, depending on dispersal for survival and having large home ranges, and thus are generally not threatened. This generalistic nature of many of the inhabitants of temporary wetlands in the region is hypothesized as one of the reasons why many of the taxa do not display high levels of endemism. There are certain exceptions, such as for rock pools of the Drakensberg in the east of the region, and the lowland pools of the Western Cape province, both of which are

1252 hotspots of ostracod and cladoceran endemism and richness (Martens et al., 1998; Martens, 1253 2001; de Moor \& Day, 2013; Van Damme et al., 2013). (anostracan) species richness is depicted as an array of hotspots throughout the region, not 
being centered on any particular area and does not appear to be governed by any particular

1257 climatic factor (Hamer \& Brendonck, 1997). The large branchiopod crustaceans show the

1258 greatest potential as 'flagships' for conservation of temporary wetlands in the region, given

1259 their relatively large size and uniqueness in terms of adaptations to life in the temporary

1260 aquatic realm. The odonates, molluscs and anostracans are the only groups covered in this

1261 review to have an appreciable amount of IUCN Red List information in the region. The

1262 freshwater molluscs appear to be have few threatened species in the region (10 species, $8.6 \%$

1263 of the fauna, Kristensen et al., 2009). Anostracan Red List information is still far from

1264 comprehensive. For instance, De Roeck et al. (2007) reported that only two of the 14

1265 anostracan species known to occur in the Western Cape province of SA were listed by IUCN

1266 and that insufficient data were available to determine the IUCN Red Data Category of six of

1267 these species. Of the 46 anostracan species reported for southern Africa by Hamer \&

1268 Brendonck (1997), two were considered by IUCN (1994) as 'Critically Endangered', four

1269 were 'Endangered', three were 'Vulnerable' and 24 were 'Least Concern', whilst data were

1270 deficient for the categorisation of 13 species. As is the trend worldwide, the anostracans of

1271 the region are threatened by agriculture and urbanization, due to both indirect (pollution and

1272 pesticides) and direct (physical) habitat alteration arising from these activities (Brendonck et

1273 al., 2008). These factors are thought to have driven the extinction of Streptocephalus gracilis

1274 Sars, 1898 and Branchipodopsis karroensis Barnard, 1929 (De Roeck et al., 2007).

1275 We hypothesize that temporary wetland specialists such as the branchiopods (including 1276 cladocerans), ostracods and copepods, which tend to be more habitat-restricted and less

1277 capable of escaping degradation, are more likely to be affected by human impacts than for

1278 taxa that are able to easily disperse to other more favourable areas (e.g. dipterans,

1279 hemipterans, odonates and coleopterans). The sensitivity of the region's temporary wetland

1280 invertebrates to human impacts such as pollution and habitat alteration is a topic still under

1281 investigation, with some evidence indicating a resilient fauna (Bird et al., 2013), whilst other

1282 evidence is in favour of a more sensitive fauna (Bird \& Day, 2016), especially when effects

1283 are combined with climate change impacts (Dalu et al., 2017a). Whatever the case may be,

1284 what is certain is that temporary wetland habitats worlwide have been degraded and

1285 destroyed at an alarming rate (Semlitsch \& Bodie, 1998), and various studies indicate that the

1286 situation is no different in southern Africa (De Roeck et al., 2007; Bird \& Day, 2014; Dalu et

1287 al., 2017a). 
In terms of the way forward, we cannot expect to properly understand and conserve temporary wetlands if we don't know what lives in them. As things stand, this is certainly the

1290 case in southern Africa in that we lack updated taxonomic information for many groups that

1291 inhabit these systems. This review shows that we have a base of knowledge on which to

1292 work, but the now famous stagnation of taxonomic expertise both locally and abroad (see

1293 Godfray, 2002; Wheeler et al., 2004; Agnarsson \& Kuntner, 2007; Bebber et al., 2014) is a

1294 major threat hindering the further progression of this knowledge. In addition to providing a

1295 synthesis for southern Africa, this work highlights the dearth of fundamental taxonomic

1296 information on the invertebrate fauna of temporary wetlands in the region, and constitutes a

1297 plea for more foundational taxonomic work to be initiated.

\section{Acknowledgements}

1299 We acknowledge use of infrastructure and equipment provided by the NRF-SAIAB Research

1300 Platform and the funding channelled through the NRF-SAIAB Institutional Support system.

1301 This study was partially funded by the National Research Foundation (Grant No. 110507).

1302 Any opinions, findings, conclusions or recommendations expressed in this material are those

1303 of the authors, and the NRF does not accept any liability in this regard. 


\section{References}

1306 Abebe, E., I. Andrássy \& W. Traunspurger, 2006. Freshwater nematodes: ecology and taxonomy. CABI Publishing, Wallingford, UK.

1308 Abebe, E., W. Decraemer \& P. De Ley, 2008. Global diversity of nematodes (Nematoda) in freshwater. Hydrobiologia 595(1): 67-78.

Agnarsson, I. \& M. Kuntner, 2007. Taxonomy in a changing world: seeking solutions for a science in crisis. Systematic Biology 56(3): 531-539.

Anlauf, A., 1990. Cyst formation of Tubifex tubifex (Müller) — an adaptation to survive food deficiency and drought. Hydrobiologia 190(1): 79-82.

1314 Anusa, A., H. Ndagurwa \& C. Magadza, 2012. The influence of pool size on species diversity and water chemistry in temporary rock pools on Domboshawa Mountain, northern Zimbabwe. African Journal of Aquatic Science 37(1): 89-99.

Appleton, C., 2002a. Platyhelminthes. In Day, J. \& I. de Moor (eds) Guides to the freshwater invertebrates of southern Africa Volume 5: Non-Arthropods. WRC Report No. TT 167/02, Water Research Commission, Pretoria, 88-110.

Armitage, P. D., 1995. Behaviour and ecology of adults. In Armitage, P. D., P. S. Cranston \& L. C. V. Pinder (eds) The Chironomidae: biology and ecology of non-biting midges. Appleton, C. C., B. A. Curtis, L. E. Alonso \& J. Kipping, 2003. Freshwater invertebrates of the Okavango Delta, Botswana. In: Alonso, L. E. \& L.-A. Nordin (eds) RAP Bulletin

Appleton, C., 2002b. Mollusca. In Day, J. \& I. de Moor (eds) Guides to the freshwater invertebrates of southern Africa Volume 6: Arachnida and Mollusca. WRC Report No. TT 182/02, Water Research Commission, Pretoria, pp. 42-125.

Appleton, C., B. Sharp \& D. le Sueur, 1995. Wetlands and water-related parasitic diseases of man in Southern Africa. In Cowan, G. I. (ed) Wetlands of South Africa. Department of Environmental Affairs and Tourism, Pretoria, South Africa., 227-246. assessment: an overview of the results. Hydrobiologia 595(1): 627-637. 
Barber-James, H. M. \& J.-L. Gattolliat, 2012. How well are Afrotropical mayflies known? Status of current knowledge, practical applications, and future directions. Inland Waters 2(1): 1-9.

Barber-James, H. M., J.-L. Gattolliat, M. Sartori \& M. D. Hubbard, 2008. Global diversity of mayflies (Ephemeroptera, Insecta) in freshwater. Hydrobiologia 595(1): 339-350.

Barber-James, H. M. \& C. Lugo-Ortiz, 2003. Ephemeroptera. In de Moor, I., J. Day \& F. de Moor (eds) Guides to the Freshwater Invertebrates of southern Africa. vol 7: Insecta I - Ephemeroptera, Odonata and Plecoptera. WRC Report no. TT 207/03, Water Research Commission, Pretoria, 16-142.

Barnard, K., 1926. A study of the freshwater isopodan and amphipodan Crustacea of South Africa. Transactions of the Royal Society of South Africa 14(1): 139-215.

Batzer, D. \& D. Boix, 2016. Invertebrates in freshwater wetlands: an international perspective on their ecology. Springer, Switzerland.

Batzer, D. P., R. B. Rader \& S. A. Wissinger, 1999. Invertebrates in freshwater wetlands of North America: ecology and management. John Wiley and Sons.

Baxevanis, A. D., S. Maniatsi, D. Kouroupis, K. Marathiotis, I. Kappas, H. Kaiser \& T. J. Abatzopoulos, 2014. Genetic identification of South African Artemia species: invasion, replacement and co-occurrence. Journal of the Marine Biological Association of the United Kingdom 94(04): 775-785.

Bebber, D. P., J. R. Wood, C. Barker \& R. W. Scotland, 2014. Author inflation masks global capacity for species discovery in flowering plants. New Phytologist 201(2): 700-706.

Belk, D., H. Dumont \& N. Munuswamy, 1991. Studies on large branchiopod biology and aquaculture. Kluwer Academic, Belgium.

Bilton, D. T., 2013. Prosthetops wolfbergensis sp. nov.- a giant amongst the 'minute moss beetles', with new data on other members of the genus (Coleoptera, Hydraenidae). Zootaxa 3666(3): 345-357.

Bilton, D. T., 2017. Water beetles from the Bokkeveld Plateau: a semi-arid hotspot of freshwater biodiversity in the Northern Cape of South Africa. Zootaxa 4268(2): 191214.

Bilton, D. T., J. R. Freeland \& B. Okamura, 2001. Dispersal in freshwater invertebrates. Annual Review of Ecology and Systematics 32(1): 159-181.

Bilton, D. T., E. F. Toussaint, C. R. Turner \& M. Balke, 2015. Capelatus prykei gen. et sp. n.(Coleoptera: Dytiscidae: Copelatinae) - a phylogenetically isolated diving beetle from the Western Cape of South Africa. Systematic Entomology 40(3): 520-531. 
Bird, M. \& J. Day, 2014. Wetlands in changed landscapes: the influence of habitat transformation on the physico-chemistry of temporary depression wetlands. PLoS ONE 9(2): e88935.

Bird, M. S., 2012. Effects of habitat transformation on temporary wetlands in the southwestern Cape, South Africa. PhD thesis, Zoology Department, University of Cape Town.

Bird, M. S. \& J. A. Day, 2016. Impacts of terrestrial habitat transformation on temporary wetland invertebrates in a sclerophyllous Sand fynbos landscape. Hydrobiologia 782(1): 169-185.

Bird, M. S., M. C. Mlambo \& J. A. Day, 2013. Macroinvertebrates as unreliable indicators of human disturbance in temporary depression wetlands of the south-western Cape, South Africa. Hydrobiologia 720: 19-37 doi:10.1007/s10750-013-1618-2.

Biström, O. \& A. N. Nilsson, 2006. Taxonomic revision of the Ethiopian genus Canthyporus (Coleoptera Dytiscidae). Memorie della Societa Entomologica Italiana 85(1): 209306.

Boettger, K., 1974. The biology of Sphaerodema grassei ghesquierei. Studies of central African belostomatids (Heteroptera, Insecta) Archiv für Hydrobiologie 74: 100-122.

Bohonak, A. J., B. P. Smith \& M. Thornton, 2004. Distributional, morphological and genetic consequences of dispersal for temporary pond water mites. Freshwater Biology 49(2): 170-180.

Boxshall, G. A. \& D. Defaye, 2008. Global diversity of copepods (Crustacea: Copepoda) in freshwater. Hydrobiologia 595(1): 195-207.

Brain, C., 2002. Rotifera. In Day, J. \& I. de Moor (eds) Guides to the freshwater invertebrates of southern Africa Volume 5: Non-Arthropods. WRC Report No. TT 167/02, Water Research Commission, Pretoria, 116-135.

Brendonck, L., 1995. A new branchipodid genus and species (Crustacea: Branchiopoda: Anostraca) from South Africa. Zoological Journal of the Linnean Society 115(4): 359372.

Brendonck, L., 1996. Diapause, quiescence, hatching requirements: what we can learn from large freshwater branchiopods (Crustacea: Branchiopoda: Anostraca, Notostraca, Conchostraca). Hydrobiologia 320(1-3): 85-97.

Brendonck, L., 1999. Conchostraca. In Day, J., I. de Moor, B. Stewart \& A. Louw (eds) Guides to the freshwater invertebrates of southern Africa Volume 2: Crustacea I - 

Water Research Commission, Pretoria, 59-80.

Brendonck, L. \& A. Coomans, 1994. Egg morphology in African Streptocephalidae (Crustacea: Branchiopoda: Anostraca). Part 1: South of Zambezi and Kunene rivers. Archiv für Hydrobiologie 3(Suppl. 99 (Monographische Beiträge)): 313-334.

Brendonck, L. \& L. De Meester, 2003. Egg banks in freshwater zooplankton: evolutionary and ecological archives in the sediment. Hydrobiologia 491(1-3): 65-84.

Brendonck, L., L. De Meester \& B. J. Riddoch, 2000a. Regional structuring of genetic variation in short-lived rock pool populations of Branchipodopsis wolfi (Crustacea: Anostraca). Oecologia 123(4): 506-515.

Brendonck, L., M. Hamer, B. Riddoch \& M. Seaman, 2000b. Branchipodopsis speciesspecialists of ephemeral rock pools. African Journal of Aquatic Science 25(1): 98104.

Brendonck, L., E. Michels, L. De Meester \& B. Riddoch, 2002. Temporary pools are not 'enemy-free'. Hydrobiologia 486(1): 147-159.

Brendonck, L. \& B. Riddoch, 1997. Anostracans (Branchiopoda) of Botswana: morphology, distribution, diversity, and endemicity. Journal of Crustacean Biology 17(1): 111-134.

Brendonck, L., B. Riddoch, V. Van de Weghe \& T. Van Dooren, 1998. The maintenance of egg banks in very short-lived pools-a case study with anostracans (Branchiopoda). Archiv für Hydrobiologie 52(Special issues)): 141-161.

Brendonck, L. \& B. J. Riddoch, 1999. Wind-borne short-range egg dispersal in anostracans (Crustacea: Branchiopoda). Biological Journal of the Linnean Society 67(1): 87-95.

Brendonck, L., D. C. Rogers, J. Olesen, S. Weeks \& W. R. Hoeh, 2008. Global diversity of large branchiopods (Crustacea: Branchiopoda) in freshwater. Hydrobiologia 595(1): 167-176.

Brendonck, L. \& W. D. Williams, 2000. Biodiversity in wetlands of dry regions (drylands). In Gopal, B., W. J. Junk \& J. A. Davis (eds) Biodiversity in wetlands: assessment, function and conservation Volume 1. Backthuys Publishers, Leiden, The Neteherlands, 181-194.

Brittain, J. E. \& M. Sartori, 2003. Ephemeroptera. In Resh, V. H. \& R. T. Carde' (eds) Encyclopedia of Insects. Academic Press, Amsterdam, 373-380.

Brown, D. S., 1994. Freshwater snails of Africa and their medical importance. Taylor \& Francis Ltd, London, UK. 
Brucet, S., D. Boix, R. López-Flores, A. Badosa, R. Moreno-Amich \& X. D. Quintana, 2005. Zooplankton structure and dynamics in permanent and temporary Mediterranean salt marshes: taxon-based and size-based approaches. Archiv für Hydrobiologie 162(4): 535-555.

Calhoun, A. J., D. M. Mushet, K. P. Bell, D. Boix, J. A. Fitzsimons \& F. Isselin-Nondedeu, 2017. Temporary wetlands: challenges and solutions to conserving a 'disappearing' ecosystem. Biological Conservation 211: 3-11.

Capinera, J. L., 2008. Encyclopedia of Entomology. 2nd ed. Springer Science \& Business Media. 4346 pp.

Chakona, A., C. Phiri, C. H. Magadza \& L. Brendonck, 2008. The influence of habitat structure and flow permanence on macroinvertebrate assemblages in temporary rivers in northwestern Zimbabwe. Hydrobiologia 607(1): 199-209.

Clark, T. E. \& M. J. Samways, 1996. Dragonflies (Odonata) as indicators of biotope quality in the Kruger National Park, South Africa. Journal of Applied Ecology 33(5): 10011012.

Clausnitzer, V., K.-D. B. Dijkstra, R. Koch, J.-P. Boudot, W. R. Darwall, J. Kipping, B. Samraoui, M. J. Samways, J. P. Simaika \& F. Suhling, 2012. Focus on African freshwaters: hotspots of dragonfly diversity and conservation concern. Frontiers in

Cranston, P. S., 2014. A new putatively cryptobiotic midge, Polypedilum ovahimba sp. nov.(Diptera: Chironomidae), from southern Africa. Austral Entomology 53(4): 373379.

Cumberlidge, N., 2009. The status and distribution of freshwater crabs. In Smith, K. G., M. D. Diop, M. Niane \& W. R. T. Darwell (eds) The status and distribution of freshwater 
biodiversity in West Africa: IUCN and Wetlands International Report. Gland, Switzerland and Cambridge, UK, 56-72.

Curtis, B., 1991. Freshwater macro-invertebrates of Namibia. Madoqua 17(2): 163-187.

Dahms, H.-U., 1995. Dormancy in the Copepoda —an overview. Hydrobiologia 306(3): 199211.

Dalu, T., R. J. Wasserman \& M. T. Dalu, 2017a. Agricultural intensification and drought frequency increases may have landscape-level consequences for ephemeral ecosystems. Global Change Biology 23(3): 983-985.

Dalu, T., R. J. Wasserman, P. W. Froneman \& O. L. Weyl, 2017b. Trophic isotopic carbon variation increases with pond's hydroperiod: evidence from an Austral ephemeral ecosystem. Scientific Reports 7: 7572.

Dalu, T., R. J. Wasserman, T. J. Vink \& O. L. Weyl, 2017c. Sex and species specific isotopic niche specialisation increases with trophic complexity: evidence from an ephemeral pond ecosystem. Scientific Reports 7: 43229.

Dalu, T., O. L. Weyl, P. W. Froneman \& R. J. Wasserman, 2016. Trophic interactions in an austral temperate ephemeral pond inferred using stable isotope analysis. Hydrobiologia 768(1): 81-94.

Daniels, S. R., E. E. Phiri \& J. Bayliss, 2014. Renewed sampling of inland aquatic habitats in southern Africa yields two novel freshwater crab species (Decapoda: Potamonautidae: Potamonautes). Zoological Journal of the Linnean Society 171(2): 356-369.

da Silva, J.M. \& S. Willows-Munro, 2016. A review of over a decade of DNA barcoding in South Africa: A faunal perspective. African Zoology 51(1): 1-12.

Davies, R. W., L. Linton \& F. Wrona, 1982. Passive dispersal of four species of freshwater leeches (Hirudinoidea) by ducks. Freshwater Invertebrate Biology 1: 40-44.

Davis, C. L., 2011. Climate risk and vulnerability: a handbook for southern Africa. Council for Scientific and Industrial Research, Pretoria, South Africa, 92pp.

Day, J., 1990. Environmental correlates of aquatic faunal distribution in the Namib Desert. In Seely, M. K. (ed) Namib ecology: 25 years of Namib research. Transvaal Museum Monograph No. 7. Transvaal Museum, Pretoria, 99-107.

Day, J., E. Day, V. Ross-Gillespie \& A. Ketley, 2010. The assessment of temporary wetlands during dry conditions. WRC Report TT434/09, Water Research Commission, Pretoria. 
Day, J. \& J. Day, 2002. Polychaeta. In Day, J. \& I. de Moor (eds) Guides to the Freshwater Invertebrates of southern Africa. vol Volume 5: Non-Arthropods. WRC Report No. TT 167/02, Water Research Commission, Pretoria, 193-202.

De Block, M., M. A. McPeek \& R. Stoks, 2008. Stronger compensatory growth in a permanent-pond Lestes damselfly relative to temporary-pond Lestes. Oikos 117(2): 245-254.

de Klerk, A. R. \& V. Wepener, 2013. Macroinvertebrate assemblage changes as an indicator of water quality of perennial endorheic reed pans on the Mpumalanga highveld, South Africa. Journal of Environmental Protection 4: 10-21.

de Meillon, B. \& W. Wirth, 2002. Ceratopogonidae. In Day, J. \& I. de Moor (eds) Guides to the freshwater invertebrates of southern Africa Vol 9: Diptera. WRC Report No. TT 201/02, Water Research Commission, Pretoria, 50-56.

de Moor, F. \& J. Day, 2013. Aquatic biodiversity in the mediterranean region of South Africa. Hydrobiologia 719(1): 237-268.

de Moor, F. \& K. Scott, 2003. Trichoptera. In de Moor, I., J. Day \& F. C. De Moor (eds) Guides to the freshwater invertebrates of southern Africa Volume 8: Insecta II Hemiptera, Megaloptera, Neuroptera, Trichoptera and Lepidoptera. vol 8. WRC Report No. TT 214/03, 84-181.

de Necker, L., M. Ferreira, J. J. van Vuren \& W. Malherbe, 2016. Aquatic invertebrate community structure of selected endorheic wetlands (pans) in South Africa. Inland Waters 6(3): 303-313.

De Roeck, E., A. Waterkeyn \& L. Brendonck, 2010. Life-history traits of Streptocephalus purcelli Sars, 1898 (Branchiopoda, Anostraca) from temporary waters with different phenology. Water SA 36(3): 323-328.

De Roeck, E. R., T. Artois \& L. Brendonck, 2005. Consumptive and non-consumptive effects of turbellarian (Mesostoma sp.) predation on anostracans. Hydrobiologia 542(1): 103111.

De Roeck, E. R., B. J. Vanschoenwinkel, J. A. Day, Y. Xu, L. Raitt \& L. Brendonc, 2007. Conservation status of large branchiopods in the Western Cape, South Africa. Wetlands 27(1): 162-173.

Dettner, K., 1982. Description of the larvae of Acilius duvergeri (Coleoptera, Dytiscidae), with keys to larvae of European species of genus Acilius and of the European genera of subfamily Dytiscinae. Aquatic Insects 4(2): 81-88. 
Di Sabatino, A., H. Smit, R. Gerecke, T. Goldschmidt, N. Matsumoto \& B. Cicolani, 2008. Global diversity of water mites (Acari, Hydrachnidia; Arachnida) in freshwater. Hydrobiologia 595: 303-315.

Dijkstra, K.-D. B., 2003. A review of the taxonomy of African Odonata: finding ways to better identification and biogeographic insight. Cimbebasia 18: 191-206.

Dijkstra, K.-D. B., J. Kipping \& N. Mézière, 2015. Sixty new dragonfly and damselfly species from Africa (Odonata). Odonatologica 44(4): 447-678.

Dodson, S. I., 1987. Animal assemblages in temporary desert rock pools: aspects of the ecology of Dasyhelea sublettei (Diptera: Ceratopogonidae). Journal of the North American Benthological Society 6(1): 65-71.

Dumont, H. \& S. Negrea, 2002. Introduction to the class Branchiopoda. In Dumont, H. J. (ed) Guides to the Identification of the Microinvertebrates of the Continental Waters of the World 19. Backhuys Publishers, Leiden.

Dumont, H. J., 1983. Biogeography of rotifers. Hydrobiologia 104: 19-30.

Escalera-Vázquez, L. H. \& L. Zambrano, 2010. The effect of seasonal variation in abiotic factors on fish community structure in temporary and permanent pools in a tropical wetland. Freshwater Biology 55(12): 2557-2569.

Farnesi, L. C., R. F. S. Menna-Barreto, A. J. Martins, D. Valle \& G. L. Rezende, 2015. Physical features and chitin content of eggs from the mosquito vectors Aedes aegypti, Anopheles aquasalis and Culex quinquefasciatus: Connection with distinct levels of resistance to desiccation. Journal of Insect Physiology 83: 43-52.

Ferreira, M., V. Wepener \& J. J. Van Vuren, 2011. The occurrence of large branchiopod crustaceans in perennial pans: a research note. African Zoology 46(1): 176-178.

Ferreira, M., V. Wepener \& J. J. van Vuren, 2012. Aquatic invertebrate communities of perennial pans in Mpumalanga, South Africa: a diversity and functional approach. African Invertebrates 53(2): 751-768.

Forero, D., 2008. The systematics of the Hemiptera. Revista Colombiana de Entomologia 34(1): 1-21.

Forró, L., N. Korovchinsky, A. Kotov \& A. Petrusek, 2008. Global diversity of cladocerans (Cladocera; Crustacea) in freshwater. Hydrobiologia 595(1): 177-184.

Foster, G. N., D. T. Bilton \& B. Nelson, 2016. Atlas of the predaceous water beetles (Hydradephaga) of Britain and Ireland. Field Studies Council, UK. 
Foster, L., W. Malherbe, M. Ferreira \& J. J. van Vuren, 2015. Macroinvertebrate variation in endorheic depression wetlands in North West and Mpumalanga provinces, South Africa. African Journal of Aquatic Science 40(3): 287-297.

Frey, D., 1993. The penetration of cladocerans into saline waters. Hydrobiologia 267: 233248.

Frost, T. M., 1991. Porifera. In Thorpe, J. H. \& A. P. Covich (eds) Ecology and Classification of North American Freshwater Invertebrates. Academic Press, New York, 95-124.

Frouz, J., J. Matěna \& A. Ali, 2003. Survival strategies of chironomids (Diptera: Chironomidae) living in temporary habitats: a review. European Journal of Entomology 100(4): 459-466.

Fryer, G., 1988. Studies on the functional morphology and biology of the Notostraca (Crustacea: Branchiopoda). Philosophical Transactions of the Royal Society of London B: Biological Sciences 321(1203): 27-124.

Garey, J. R., S. J. McInnes \& P. B. Nichols, 2008. Global diversity of tardigrades (Tardigrada) in freshwater. Hydrobiologia 595(1): 101-106.

Gerecke, R., 2004. Taxonomy and phylogeny in African water mites of the genus Diplodontus Dugés, 1834 (Acari, Hydrachnidia, Hydryphantidae). Annales de Limnologie-International Journal of Limnology 40(1): 71-85.

Gillies, M., 1990. A revision of the African species of Centroptilum Eaton (Baetidae, Ephemeroptera). Aquatic Insects 12(2): 97-128.

Godfray, H. C. J., 2002. Challenges for taxonomy. Nature 417(6884): 17-19.

Goldschmidt, T. \& H. Smit, 2009. Studies on torrenticolid water mites mainly from South Africa-Torrenticola Piersig, 1896 and Monatractides K. Viets, 1926 (Acari: Hydrachnidia: Torrenticolidae). International Journal of Acarology 35(3): 179-234. Goudie, A. \& G. Wells, 1995. The nature, distribution and formation of pans in arid zones. Earth-Science Reviews 38(1): 1-69.

Gouws, G., B. A. Stewart \& C. A. Matthee, 2005. Lack of taxonomic differentiation in an apparently widespread freshwater isopod morphotype (Phreatoicidea: Mesamphisopidae: Mesamphisopus) from South Africa. Molecular Phylogenetics and Evolution 37(1): 289-305.

Grimaldi, D. \& M. S. Engel, 2005. Evolution of the Insects. Cambridge University Press. Gueriau, P., N. Rabet, G. Clément, L. Lagebro, J. Vannier, D. E. Briggs, S. Charbonnier, S. Olive \& O. Béthoux, 2016. A 365-million-year-old freshwater community reveals 
morphological and ecological stasis in branchiopod crustaceans. Current Biology 26(3): 383-390.

Hamer, M., 1999. Anostraca. In Day, J., I. de Moor, B. Stewart \& A. Louw (eds) Guides to the freshwater invertebrates of southern Africa Volume 2: Crustacea I - Notostraca, Anostraca, Conchostraca and Cladocera. WRC Report No. TT 121/00, Water Research Commission, Pretoria, 14-58.

Hamer, M., 2013. A national strategy for zoological taxonomy (2013-2020). South African National Biodiversity Institute, Pretoria, South Africa: 1-53.

Hamer, M. \& C. Appleton, 1991. Physical and chemical characteristics and phyllopod fauna of temporary pools in north-eastern Natal, Republic of South Africa. Hydrobiologia 212: 95-104.

Hamer, M. \& L. Brendonck, 1997. Distribution, diversity and conservation of Anostraca (Crustacea: Branchiopoda) in southern Africa. Hydrobiologia 359: 1-12.

Hamer, M., L. Brendonck, A. Coomans \& C. Appleton, 1994. A review of African Streptocephalidae (Crustacea: Branchiopoda: Anostraca). Part 1: South of Zambezi and Kunene rivers. Archiv für Hydrobiologie 3(Suppl. 99 (Monographische Beiträge)): 235-277.

Hamer, M. \& K. Martens, 1998. The large Branchiopoda (Crustacea) from temporary habitats of the Drakensberg region, South Africa. Hydrobiologia 384(1-3): 151-165.

Hamer, M. \& N. Rayner, 1995. A note on the taxonomy and distribution of Triops Schrank (Crustacea: Branchiopoda: Notostraca) in southern Africa. Annals of the Natal Museum 36: 9-19.

Hamer, M. \& N. Rayner, 1996. A note on the unusual crustacean community of a temporary pool in the Northern Cape. Southern African Journal of Aquatic Science 22(1-2): 100104.

Hamer, M. L., 1989. Studies on the phyllopod fauna of ephemeral pools in north-eastern Natal. MSc thesis, University of Natal, Pietermaritzburg, South Africa. 192 pp.

Harris, P. M., B. R. Roosa \& L. Norment, 2002. Underground dispersal by amphipods (Crangonyx pseudogracilis) between temporary ponds. Journal of Freshwater Ecology 17(4): 589-594.

Harrison, A. D., 2002. Chironomidae. In Day, J. \& I. de Moor (eds) Guides to the freshwater invertebrates of southern Africa Volume 9: Diptera. WRC Report No. TT 201/02, Water Research Commission, Pretoria. 
1635 Hassall, C. \& D. J. Thompson, 2008. The effects of environmental warming on Odonata: a review. International Journal of Odonatology 11(2): 131-153.

Heeg, J., 2002a. Porifera. In Day, J. \& I. de Moor (eds) Guides to the Freshwater Invertebrates of southern Africa. vol 5: Non-Arthropods, WRC Report No. TT 167/02, Water Research Commission, Pretoria, 59-73.

1640 Heeg, J., 2002b. Gastrotricha. In Day, J. \& I. de Moor (eds) Guides to the Freshwater

Heeg, J., 2002c. Bryozoa. In Day, J. \& I. de Moor (eds) Guides to the Freshwater Invertebrates of southern Africa. vol 5: Non-Arthropods. WRC Report No. TT 167/02, Water Research Commission, Pretoria, 173-188.

1646 Heyns, J., 2002. Checklist of free living nematodes recorded from freshwater habitats in 1647 Southern Africa. Water SA 28(4): 449-456.

1648 Hinton, H. E., 1953. Some adaptations of insects to environments that are alternately dry and 1649 flooded, with some notes on the habits of the Stratiomyidae. Transactions of the Society for British Entomology 11: 209-227.

Hinton, H. E., 1960. A fly larva that tolerates dehydration and temperatures of $-270^{\circ}$ to + $102^{\circ}$ C. Nature 188: 336-337.

Holsinger, J. R. \& G. W. Dickson, 1977. Burrowing as a means of survival in the troglobitic amphipod crustacean Crangonyx antennatus Packard (Crangonyctidae). Hydrobiologia 54(3): 195-199.

Horne, D. \& K. Martens, 1998. An assessment of the importance of resting eggs for the evolutionary success of Mesozoic non-marine cypridoidean Ostracoda (Crustacea). Archiv für Hydrobiologie 52: 549-561.

Hynes, H., 1955. Biological notes on some East African aquatic Heteroptera. Physiological Entomology 30(4-6): 43-54.

1667 Jäch, M. A. \& M. Balke, 2008. Global diversity of water beetles (Coleoptera) in freshwater. Hydrobiologia 595(1): 419-442. 
Jannot, J. E., 2009. Life history plasticity and fitness in a caddisfly in response to proximate cues of pond-drying. Oecologia 161(2): 267-277.

Jannot, J. E., S. A. Wissinger \& J. R. Lucas, 2008. Diet and a developmental time constraint alter life-history trade-offs in a caddis fly (Trichoptera: Limnephilidae). Biological Journal of the Linnean Society 95(3): 495-504.

Jansen van Rensburg, C., 1976. An identification key to the water mite families of the Ethiopian region. Journal of the Limnological Society of Southern Africa 2(1): 11-20.

Jansen van Rensburg, C. \& J. Day, 2002. Water mites In Day, J. \& I. de Moor (eds) Guides to the Freshwater Invertebrates of southern Africa. vol 6: Arachnida and Mollusca. WRC Report no. TT 182/02, Water Research Commission, Pretoria, 23-41.

Jeffries, M., 2005. Small ponds and big landscapes: the challenge of invertebrate spatial and temporal dynamics for European pond conservation. Aquatic Conservation: Marine and Freshwater Ecosystems 15(6): 541-547.

Jocqué, M., L. Brendonck, B. J. Riddoch \& K. Martens, 2010. On Amphibolocypris arida sp. nov.(Crustacea, Ostracoda), from rock pools in Botswana (southern Africa). Zootaxa 2408: 47-58.

Jocqué, M., K. Martens, B. Riddoch \& L. Brendonck, 2006. Faunistics of ephemeral rock pools in southeastern Botswana. Archiv für Hydrobiologie 165(3): 415-431.

Johansson, F. \& F. Suhling, 2004. Behaviour and growth of dragonfly larvae along a permanent to temporary water habitat gradient. Ecological Entomology 29(2): 196202.

Jones, M., 2002. Developing a classification system for Western Cape wetlands. MSc thesis, Zoology Department, University of Cape Town.

Jupp, P., B. McIntosh \& E. Nevill, 1980. A survey of the mosquito and Culicoides faunas at two localities in the Karoo region of South Africa with some observations of bionomics. The Onderstepoort journal of veterinary research 47(1): 1-6.

Kaiser, H., A. Gordon \& T. Paulet, 2006. Review of the African distribution of the brine shrimp genus Artemia. Water SA 32(4): 597-603.

Kalkman, V. J., V. Clausnitzer, K.-D. B. Dijkstra, A. G. Orr, D. R. Paulson \& J. van Tol, 2008. Global diversity of dragonflies (Odonata) in freshwater. Hydrobiologia 595(1): 351-363.

Kipping, J., 2010. The dragonflies and damselflies of Botswana: an annotated checklist with notes on distribution, phenology, habitats and Red List status of the species (Insecta: Odonata). Mauritiana (Altenberg) 21: 126-204. 
1703

1704

1705

1706

1707

1708

1709

1710

1711

1712

1713

1714

1715

1716

1717

1718

1719

1720

1721

1722

1723

1724

1725

1726

1727

1728

1729

1730

1731

1732

1733

1734

1735

Kneitel, J. M., 2016. Climate-driven habitat size determines the latitudinal diversity gradient in temporary ponds. Ecology 97(4): 961-968.

Korn, M. \& A. K. Hundsdoerfer, 2006. Evidence for cryptic species in the tadpole shrimp Triops granarius (Lucas, 1864)(Crustacea: Notostraca). Zootaxa 1257: 57-68.

Korovchinsky, N., 2006. The Cladocera (Crustacea: Branchiopoda) as a relict group. Zoological Journal of the Linnean Society 147(1): 109-124.

Kristensen, T. K., C. C. Appleton, B. Curtis \& A.-S. Stensgaard, 2009. The status and distribution of freshwater molluscs. In Darwall, W., D. Tweddle, K. Smith \& P. Skelton (eds) The status and distribution of freshwater biodiversity in southern Africa. IUCN, Gland, Switzerland, 38-47.

Lahr, J., 1997. Ecotoxicology of organisms adapted to life in temporary freshwater ponds in arid and semi-arid regions. Archives of Environmental Contamination and Toxicology 32(1): 50-57.

Lahr, J., K. B. Ndour, A. Badji \& P. S. Diouf, 1999. Phenology of invertebrates living in a sahelian temporary pond. Hydrobiologia 405: 189-205.

Lund, J. O., S. A. Wissinger \& B. L. Peckarsky, 2016. Caddisfly behavioral responses to drying cues in temporary ponds: implications for effects of climate change. Freshwater Science 35(2): 619-630.

Manconi, R. \& R. Pronzato, 2008. Global diversity of sponges (Porifera: Spongillina) in freshwater. Hydrobiologia 595(1): 27-33.

Martens, A., R. Jödicke \& F. Suhling, 2003. An annotated checklist of the Odonata of Namibia. Cimbebasia 18: 139-160.

Martens, K., 2001. Ostracoda. In Day, J., I. de Moor, B. Stewart \& L. AE (eds) Guides to the freshwater invertebrates of southern Africa Volume 3: Crustacea II - Ostracoda, Copepoda and Branchiura. WRC Report no. TT 148/01, Water Research Commission, Pretoria, 78-123.

Martens, K., 2003. On a remarkable South African giant ostracod (Crustacea, Ostracoda, Cyprididae) from temporary pools, with additional appendages. Hydrobiologia 500: 115-130.

Martens, K., 2007. On a new species and genus in the Cypridini (Crustacea, Ostracoda, Cyprididae) from South Africa, with a phylogenetic analysis of the tribe and a discussion on the genus concept in this group. Journal of Natural History 41(5-8): 381-399. 
Martens, K., B. Davies, A. Baxter \& M. Meadows, 1996. A contribution to the taxonomy and ecology of the Ostracoda (Crustacea) from Verlorenvlei (Western Cape, South Africa). African Zoology 31(1): 23-36.

Martens, K., M. Hamer \& M. Coke, 1998. A preliminary account of the diversity of nonmarine Ostracoda (Crustacea) in KwaZulu-Natal, South Africa. Lammergeyer 45: 1731.

Martin, P., E. Martinez-Ansemil, A. Pinder, T. Timm \& M. J. Wetzel, 2008. Global diversity of oligochaetous clitellates ("Oligochaeta"; Clitellata) in freshwater. Hydrobiologia 595(1): 117-127.

Mathers, T. C., R. L. Hammond, R. A. Jenner, B. Hänfling \& A. Gomez, 2013. Multiple global radiations in tadpole shrimps challenge the concept of 'living fossils'. PeerJ 1: e62.

Matzke-Karasz, R. \& K. Martens, 2007. On Afrocypris barnardi GO Sars, 1924 (Ostracoda), a second giant ostracode with additional appendages. Crustaceana 80(5): 603-623.

McDermott, E. G. \& B. A. Mullens, 2014. Desiccation tolerance in the eggs of the primary North American bluetongue virus vector, Culicoides sonorensis (Diptera: Ceratopogonidae), and implications for vector persistence. Journal of Medical Entomology 51(6): 1151-1158.

McKee, P. \& G. Mackie, 1980. Desiccation resistance in Sphaerium occidentale and Musculium securis (Bivalvia: Sphaeriidae) from a temporary pond. Canadian Journal of Zoology 58(9): 1693-1696.

Mckenna, D. D., A. L. Wild, K. Kanda, C. L. Bellamy, R. G. Beutel, M. S. Caterino, C. W. Farnum, D. C. Hawks, M. A. Ivie \& M. L. Jameson, 2015. The beetle tree of life reveals that Coleoptera survived end-Permian mass extinction to diversify during the Cretaceous terrestrial revolution. Systematic Entomology 40(4): 835-880.

McLachlan, A. \& M. Cantrell, 1980. Survival strategies in tropical rain pools. Oecologia 47(3): 344-351.

McLachlan, A. \& R. Ladle, 2001. Life in the puddle: behavioural and life-cycle adaptations in the Diptera of tropical rain pools. Biological Reviews 76(3): 377-388.

Meintjes, S., 1996. Seasonal changes in the invertebrate community of small shallow ephemeral pans at Bain's Vlei, South Africa. Hydrobiologia 317(1): 51-64.

Meyer, H. A. \& J. G. Hinton, 2009. The Tardigrada of southern Africa, with the description of Minibiotus harrylewisi, a new species from KwaZulu-Natal, South Africa (Eutardigrada: Macrobiotidae). African Invertebrates 50(2): 255-268. 
1770

1771

1772

1773

1774

1775

1776

1777

1778

1779

1780

1781

1782

1783

1784

1785

1786

1787

1788

1789

1790

1791

1792

1793

1794

1795

1796

1797

1798

1799

1800

1801

Miller, J. R., J. Huang, J. Vulule \& E. D. Walker, 2007. Life on the edge: African malaria mosquito (Anopheles gambiae s.1.) larvae are amphibious. Naturwissenschaften 94(3): 195-199.

Mlambo, M. C., M. S. Bird, C. C. Reed \& J. A. Day, 2011. Diversity patterns of temporary wetland macroinvertebrate assemblages in the south-western Cape, South Africa. African Journal of Aquatic Science 36(3): 299-308.

Møbjerg, N., K. A. Halberg, A. Jørgensen, D. Persson, M. Bjørn, H. Ramløv \& R. M. Kristensen, 2011. Survival in extreme environments-on the current knowledge of adaptations in tardigrades. Acta Physiologica 202(3): 409-420.

Montalto, L. \& M. Marchese, 2005. Cyst formation in Tubificidae (Naidinae) and Opistocystidae (Annelida, Oligochaeta) as an adaptive strategy for drought tolerance in fluvial wetlands of the Paraná River, Argentina. Wetlands 25(2): 488-494.

Morse, J. C., 2011. The Trichoptera world checklist. Zoosymposia 5(1): 372-380.

Newell, R. L. \& B. R. Hossack, 2009. Large, wetland-associated mayflies (Ephemeroptera) of Glacier National Park, Montana. Western North American Naturalist 69(3): 335342.

Nhiwatiwa, T., L. Brendonck \& T. Dalu, 2017a. Understanding factors structuring zooplankton and macroinvertebrate assemblages in ephemeral pans. LimnologicaEcology and Management of Inland Waters 64: 11-19.

Nhiwatiwa, T., L. Brendonck, A. Waterkeyn \& B. Vanschoenwinkel, 2011. The importance of landscape and habitat properties in explaining instantaneous and long-term distributions of large branchiopods in subtropical temporary pans. Freshwater Biology 56(10): 1992-2008.

Nhiwatiwa, T. \& T. Dalu, 2017. Seasonal variation in pans in relation to limno-chemistry, size, hydroperiod, and river connectivity in a semi-arid subtropical region. Physics and Chemistry of the Earth, Parts A/B/C 97: 37-45.

Nhiwatiwa, T., T. Dalu \& L. Brendonck, 2017b. Streptocephalus sangoensis $\mathrm{n}$. sp.(Anostraca, Streptocephalidae), a new large branchiopod species for southern Africa. Crustaceana 90(6): 673-683.

Nhiwatiwa, T., A. Waterkeyn, B. Riddoch \& L. Brendonck, 2014. A hotspot of large branchiopod diversity in south-eastern Zimbabwe. African Journal of Aquatic Science 39(1): 57-65. 
Nicolet, P., J. Biggs, G. Fox, M. J. Hodson, C. Reynolds, M. Whitfield \& P. Williams, 2004. The wetland plant and macroinvertebrate assemblages of temporary ponds in England and Wales. Biological Conservation 120: 261-278.

Nilsson, A. N., 1986a. Life cycles and habitats of the northern European Agabini (Coleoptera, Dytiscidae). Entomologica Basiliensia 11: 391-417.

Nilsson, A. N., 1986b. Larval morphology and phenology of four Fennoscandian species of Hydroporus Clairville (Coleoptera: Dytiscidae), with a preliminary key to the known larvae. Aquatic Insects 8(3): 141-153.

Nilsson, A. N., 1986c. Community structure in the Dytiscidae (Coleoptera) of a northern Swedish seasonal pond. Annales Zoologici Fennici 23(1): 39-47.

Oosthuizen, J. \& M. Siddall, 2002. Hirudinea. In Day, J. \& I. de Moor (eds) Guides to the

Pešić, V., D. Cook, R. Gerecke \& H. Smit, 2013. The water mite family Mideopsidae (Acari: Hydrachnidia): a contribution to the diversity in the Afrotropical region and taxonomic changes above species level. Zootaxa 3720(1): 1-75.

Peters, J., 1972. The ecology of Tarn Dub. Vasculum 57: 42-50. evolutionary aspects of light-induced dormancy termination in a temporary pond crustacean. Freshwater Science 32(2): 517-524. 
Rayner, N., 1999. Notostraca. In Day, J., I. de Moor, B. Stewart \& A. Louw (eds) Guides to the freshwater invertebrates of southern Africa Volume 2: Crustacea I - Notostraca, Anostraca, Conchostraca and Cladocera. WRC Report no. TT 121/00, Water Research Commission, Pretoria, 7-13.

Rayner, N., 2000. Distribution and biogeography of the Paradiaptominae (Copepoda: Calanoida: Diaptomidae). African Journal of Aquatic Sciences 25(1): 93-97.

Rayner, N., 2001. Copepoda. In Day, J., I. de Moor, B. A. Stewart \& A. Louw (eds) Guides to the freshwater invertebrates of southern Africa Volume 3: Crustacea II - Ostracoda, Copepoda and Branchiura. WRC Report No. TT 148/01, Water Research Commission, Pretoria, 78-123.

Rayner, N., 2002. Tardigrada Guides to the Freshwater Invertebrates of southern Africa. vol 5: Non-Arthropods. WRC Report No. TT 167/02, Water Research Commission, Pretoria, 189-192.

Rayner, N. \& C. Appleton, 2002. Nematomorpha. In Day, J. \& I. de Moor (eds) Guides to the Freshwater Invertebrates of southern Africa. vol 5: Non-Arthropods. WRC Report No. TT 167/02, Water Research Commission, Pretoria, 162-165.

Rayner, N., C. Appleton \& N. Millard, 2002. Cnidaria. In Day, J. \& I. de Moor (eds) Guides to the Freshwater Invertebrates of southern Africa. vol 5: Non-Arthropods. WRC Report No. TT 167/02, Water Research Commission, Pretoria, 74-87.

Rayner, N. \& J. Heeg, 1994. Distribution patterns of the Diaptomidae (Calanoida: Copepoda) in southern Africa. Hydrobiologia 272: 47-75.

Rayner, N. A., 1998. Paradiaptomus peninsularis, P. hameri and P. warreni, three new species of Paradiaptomus (Calanoida: Diaptomidae) from South Africa. Hydrobiologia 391(1-3): 87-98.

Reavell, P., 2003. Hemiptera. In de Moor, I., J. Day \& F. de Moor (eds) Guides to the freshwater invertebrates of southern Africa Volume 8: Insecta II Hemiptera, Megaloptera, Neuroptera, Trichoptera and Lepidoptera. WRC Report No. TT 214/03, Water Research Commission, Pretoria, 16-71.

Rehn, A. C., 2003. Phylogenetic analysis of higher-level relationships of Odonata. Systematic Entomology 28(2): 181-240.

Reid, J. \& C. Williamson, 2010. Copepoda. In Thorp , J. \& A. Covich (eds) Ecology and classification of North American freshwater invertebrates. Academic Press, 915-954. 
Reynolds, J., 2000. Invertebrate communities of turloughs (temporary lakes) in southeast Galway, Ireland. Internationale Vereinigung für theoretische und angewandte Limnologie: Verhandlungen 27(3): 1679-1684.

Riato, L., C. Van Ginkel \& J. C. Taylor, 2014. Zooplankton and diatoms of temporary and permanent freshwater pans in the Mpumalanga Highveld region, South Africa. African Zoology 49(1): 113-127.

Ribera, I. \& M. Balke, 2007. Recognition of a species-poor, geographically restricted but morphologically diverse Cape lineage of diving beetles (Coleoptera: Dytiscidae: Hyphydrini). Journal of Biogeography 34(7): 1220-1232.

Ricci, C. \& M. Balsamo, 2000. The biology and ecology of lotic rotifers and gastrotrichs. Freshwater Biology 44(1): 15-28.

Robinson, C. \& T. Buser, 2007. Density-dependent life history differences in a stream mayfly (Deleatidium) inhabiting permanent and intermittent stream reaches. New Zealand Journal of Marine and Freshwater Research 41(3): 265-271.

Rogers, D., 2009. Branchiopoda (Anostraca, Notostraca, Laevicaudata, Spinicaudata, Cyclestherida). Encyclopedia of inland waters 2: 242-249.

Rogers, D. C., 2014. Larger hatching fractions in avian dispersed anostracan eggs (Branchiopoda). Journal of Crustacean Biology 34(2): 135-143.

Rogers, D. C., 2015. A conceptual model for anostracan biogeography. Journal of Crustacean Biology 35(5): 686-699.

Rogers, D. C., N. Rabet \& S. C. Weeks, 2012. Revision of the extant genera of Limnadiidae (Branchiopoda: Spinicaudata). Journal of Crustacean Biology 32(5): 827-842.

Rogers, D. C., N. Rabet \& S. C. Weeks, 2016. Gondwanalimnadia (Branchiopoda: Spinicaudata), replacement name for Afrolimnadia (Limnadiidae), junior homonym of Afrolimnadia (Lioestheriidae). Journal of Crustacean Biology 36(1): 105-105.

Rubaba, O., M. Chimbari \& S. Mukaratirwa, 2016. The role of snail aestivation in transmission of schistosomiasis in changing climatic conditions. African Journal of Aquatic Science 41(2): 143-150.

Ruhí, A., D. Boix, S. Gascón, J. Sala \& D. P. Batzer, 2013. Functional and phylogenetic relatedness in temporary wetland invertebrates: current macroecological patterns and implications for future climatic change scenarios. PLoS ONE 8(11): e81739.

Sabatelli, S., P. Audisio, G. Antonini, E. Solano, A. Martinoli \& M. Trizzino, 2016. Molecular ecology and phylogenetics of the water beetle genus Ochthebius revealed 
multiple independent shifts to marine rockpools lifestyle. Zoologica Scripta 45(2): 175-186.

Sabatelli, S., P. Audisio, M. Trizzino \& A. Di Giulio, 2013. Description of the larva of Ochthebius capicola (Coleoptera: Hydraenidae) from marine rockpools of South Africa. Zootaxa 3683(3): 280-288.

Samways, M., 1999. Diversity and conservation status of South African dragonflies (Odonata). Odonatologica 28(1): 13-62.

Samways, M. J., 2004. Critical species of Odonata in southern Africa. International Journal of Odonatology 7(2): 255-262.

1910 Samways, M. J., 2008. Dragonflies and damselflies of South Africa. Pensoft Publishers.

1911 Samways, M. J., 2010. Extreme weather and climate change impacts on South African 1912 dragonflies. In Ott, J. (ed) Monitoring Climate Change with Dragonflies. Pensoft, 1913 Sophia, Bulgaria, pp. 73-84.

1914 Samways, M. J. \& J. P. Simaika, 2016. Manual of freshwater assessment for South Africa:

1915 Dragonfly Biotic Index, South African National Biodiversity Institute, Pretoria.

1916 Sartori, M. \& H. Barber-James, 2018. World checklist on Ephemeroptera. In: The Freshwater Animal Diversity Assessment (FADA) Belgium http://fadabiodiversitybe/group/show/35 Updated February 2018.

1919 Schiel, F.-J. \& R. Buchwald, 2015. Hatching phenology of Odonata species inhabiting

Schmidt-Rhaesa, A. \& R. Perissinotto, 2016. Chordodes ferox, a new record of horsehair worms (Nematomorpha, Gordiida) from South Africa. Zookeys 566: 1-11.

Scott, K. M. F., 1970. Some notes on the trichoptera of standing waters in Africa, mainly south of the Zambezi. Hydrobiologia 35(2): 177-195.

1926 Seaman, M., D. Kok, B. Von Schlichting \& A. Kruger, 1991. Natural growth and reproduction in Triops granarius (Lucas)(Crustacea: Notostraca). Hydrobiologia 212: 87-94.

Seaman, M., D. Kok \& M. Watson, 1999. Cladocera. In Day, J., I. de Moor, B. Stewart \& A. Louw (eds) Guides to the freshwater invertebrates of southern Africa Volume 2: Crustacea I - Notostraca, Anostraca, Conchostraca and Cladocera. WRC Report No. TT 121/00, Water Research Commission, Pretoria, 81-110.

Semlitsch, R. D. \& J. R. Bodie, 1998. Are small, isolated wetlands expendable? Conservation Biology 12(5): 1129-1133. 
Short, A. E. \& J. K. Liebherr, 2007. Systematics and biology of the endemic water scavenger beetles of Hawaii (Coleoptera: Hydrophilidae, Hydrophilini). Systematic Entomology 32(4): 601-624.

Short, A. E. Z., 2018. Systematics of aquatic beetles (Coleoptera): current state and future directions. Systematic Entomology 43: 1-18.

Silberbauer, M. J. \& J. M. King, 1991. The distribution of wetlands in the south-western Cape Province, South Africa. South African Journal of Aquatic Science 17(1-2): 6581.

Simaika, J. P., M. J. Samways \& P. P. Frenzel, 2016. Artificial ponds increase local dragonfly diversity in a global biodiversity hotspot. Biodiversity and Conservation 25(10): 1921-1935.

Simovich, M. A. \& S. A. Hathaway, 1997. Diversified bet-hedging as a reproductive strategy of some ephemeral pool anostracans (Branchiopoda). Journal of Crustacean Biology 17(1): 38-44.

Smirnov, N., 2008. Check-list of the South-African Cladocera (Crustacea: Branchiopoda). Zootaxa 1788: 47-56.

Smit, H., 2012. New records of the water mite family Arrenuridae from the Afrotropical region, with the description of 11 new species and two new subspecies (Acari: Hydrachnidia). Zootaxa 3187: 1-31.

Spencer, M., S. S. Schwartz \& L. Blaustein, 2002. Are there fine-scale spatial patterns in community similarity among temporary freshwater pools? Global Ecology and Biogeography 11(1): 71-78.

Strachan, S. R., E. T. Chester \& B. J. Robson, 2015. Freshwater invertebrate life history strategies for surviving desiccation. Springer Science Reviews 3(1): 57-75.

Suárez-Morales, E. \& N. A. Rayner, 2004. New records for the South African diaptomid fauna with a complementary description of Paradiaptomus lamellatus Sars (Copepoda, Diaptomidae). Journal of Natural History 38(22): 2803-2819.

Suárez-Morales, E., R. Wasserman \& T. Dalu, 2015. A new species of Lovenula Schmeil (Copepoda, Calanoida, Diaptomidae) from the Eastern Cape Province of South Africa. Crustaceana 88(3): 324-342.

Suhling, F., R. Jödicke \& W. Schneider, 2003. Odonata of African arid regions-are there desert species. Cimbebasia 18: 207-224. 
Suhling, F., G. Sahlén, J. Kasperski \& D. Gaedecke, 2005. Behavioural and life history traits

1968

1969

1970

1971

1972

1973

1974

1975

1976

1977

1978

1979

1980

1981

1982

1983

1984

1985

1986

1987

1988

1989

1990

1991

1992

1993

1994

1995

1996

1997

1998

1999

2000 in temporary and perennial waters: comparisons among three pairs of sibling dragonfly species. Oikos 108(3): 609-617.

Suhling, F., M. Samways, J. Simaika \& J. Kipping, 2009. The status and distribution of dragonflies (Odonata). In Darwall, W., K. Smith, D. Tweddle \& P. Skelton (eds) The status and distribution of freshwater biodiversity in southern Africa. IUCN, Gland/Cambridge, pp. 48-65.

Tawfik, M., 1969. Life-history of the giant water-bug, Lethocerus niloticus Stael (Hemiptera: Belostomatidae). Bulletin de la Société entomologique d'Egypte 53: 299-310.

Tobias, D. \& W. Tobias, 2008. Trichoptera africana. Available from: http://trichoptera.insects-online.de/Trichoptera\%20africana/index.htm.

Todaro, M., R. Perissinotto \& S. Bownes, 2013. Neogosseidae (Gastrotricha, Chaetonotida) from the iSimangaliso Wetland Park, KwaZulu-Natal, South Africa. Zookeys 315: 7794.

Tuytens, K., B. Vanschoenwinkel, B. Clegg, T. Nhiwatiwa \& L. Brendonck, 2015. Exploring links between geology, hydroperiod, and diversity and distribution patterns of anostracans and notostracans (Branchiopoda) in a tropical savannah habitat in SE Zimbabwe. Journal of Crustacean Biology 35(3): 309-318.

Tuytens, K., B. Vanschoenwinkel, A. Waterkeyn \& L. Brendonck, 2014. Predictions of climate change infer increased environmental harshness and altered connectivity in a cluster of temporary pools. Freshwater Biology 59(5): 955-968.

Urban, M. C., 2004. Disturbance heterogeneity determines freshwater metacommunity structure. Ecology 85(11): 2971-2978.

Van Damme, K., E. I. Bekker \& A. A. Kotov, 2013. Endemism in the Cladocera (Crustacea: Branchiopoda) of Southern Africa. Journal of Limnology 72(3): 440-463.

Van Damme, K. \& H. J. Dumont, 1999. A drought-resistant larva of Pantala flavescens (Fabricius, 1798)(Odonata: Libellulidae) in the Lençóis Maranhenses, NE-Brazil. International Journal of Odonatology 2(1): 69-76.

van Hoven, W. \& J. Day, 2002. Oligochaeta. In Day, J. \& I. de Moor (eds) Guides to the Freshwater Invertebrates of southern Africa. vol 5: Non-Arthropods. WRC Report No. TT 167/02, Water Research Commission, Pretoria, 203-236.

Van Steenkiste, N., P. Davison \& T. Artois, 2010. Bryoplana xerophila n.g.n. sp., a new limnoterrestrial microturbellarian (Platyhelminthes, Typhloplanidae, Protoplanellinae) from epilithic mosses, with notes on its ecology. Zoological Science 27(3): 285-291. 
Vandekerkhove, J., G. Louette, L. Brendonck \& L. De Meester, 2005. Development of cladoceran egg banks in new and isolated pools. Archiv für Hydrobiologie 162(3): 339-347.

Vanschoenwinkel, B., F. Buschke \& L. Brendonck, 2013. Disturbance regime alters the impact of dispersal on alpha and beta diversity in a natural metacommunity. Ecology 94(11): 2547-2557.

Vanschoenwinkel, B., C. De Vries, M. Seaman \& L. Brendonck, 2007. The role of metacommunity processes in shaping invertebrate rock pool communities along a dispersal gradient. Oikos 116(8): 1255-1266.

Vanschoenwinkel, B., S. Gielen, M. Seaman \& L. Brendonck, 2009. Wind mediated dispersal of freshwater invertebrates in a rock pool metacommunity: differences in dispersal capacities and modes. Hydrobiologia 635(1): 363-372.

Vanschoenwinkel, B., S. Gielen, H. Vandewaerde, M. Seaman \& L. Brendonck, 2008. Relative importance of different dispersal vectors for small aquatic invertebrates in a rock pool metacommunity. Ecography 31(5): 567-577.

Vanschoenwinkel, B., T. Pinceel, M. P. Vanhove, C. Denis, M. Jocque, B. V. Timms \& L. Brendonck, 2012. Toward a global phylogeny of the "living fossil" crustacean order of the Notostraca. PLoS ONE 7(4): e34998.

Vanschoenwinkel, B., M. Seaman \& L. Brendonck, 2010a. Hatching phenology, life history and egg bank size of fairy shrimp Branchipodopsis spp.(Branchiopoda, Crustacea) in relation to the ephemerality of their rock pool habitat. Aquatic Ecology 44(4): 771780.

Vanschoenwinkel, B., A. Waterkeyn, M. Jocqué, L. Boven, M. Seaman \& L. Brendonck, 2010b. Species sorting in space and time-the impact of disturbance regime on community assembly in a temporary pool metacommunity. Journal of the North American Benthological Society 29(4): 1267-1278.

Vanschoenwinkel, B., A. Waterkeyn, T. Nhiwatiwa, T. Pinceel, E. Spooren, A. Geerts, B. Clegg \& L. Brendonck, 2011. Passive external transport of freshwater invertebrates by elephant and other mud-wallowing mammals in an African savannah habitat. Freshwater Biology 56(8): 1606-1619.

Vera, C., P. Bremond, R. Labbo, F. Mouchet, E. Sellin, D. Boulanger, J. Pointier, B. Delay \& B. Sellin, 1995. Seasonal fluctuations in population densities of Bulinus senegalensis and B. truncatus (Planorbidae) in temporary pools in a focus of Schistosoma 
haematobium in Niger: implications for control. Journal of Molluscan Studies 61(1): 79-88.

Wasserman, R. J., M. E. Alexander, D. Barrios-O'Neill, O. L. Weyl \& T. Dalu, 2016a. Using functional responses to assess predator hatching phenology implications for pioneering prey in arid temporary pools. Journal of Plankton Research 38(1): 154158.

Wasserman, R. J., M. E. Alexander, O. L. Weyl, D. Barrios-O'Neill, P. W. Froneman \& T. Dalu, 2016b. Emergent effects of structural complexity and temperature on predatorprey interactions. Ecosphere 7(2): e01239.

Wasserman, R. J., M. Weston, O. L. Weyl, P. W. Froneman, R. J. Welch, T. J. Vink \& T. Dalu, 2018. Sacrificial males: the potential role of copulation and predation in contributing to copepod sex-skewed ratios. Oikos doi: 10.1111/oik.04832.

Weir, J. S., 1966. Ecology and zoogeography of aquatic Hemiptera from temporary pools in Central Africa. Hydrobiologia 28(1): 123-128.

Wharton, D. A., 2004. Survival strategies. In Gaugler, R. \& A. L. Bilgrami (eds) Nematode Behaviour. CABI Publishing, Wallingford, UK, 371-399.

Wheeler, Q. D., P. H. Raven \& E. O. Wilson, 2004. Taxonomy: Impediment or Expedient? Science 303(5656): 285.

Wickson, S., E. Chester \& B. Robson, 2012. Aestivation provides flexible mechanisms for survival of stream drying in a larval trichopteran (Leptoceridae). Marine and Freshwater Research 63(9): 821-826.

Wiggins, G. B., 1973. Contribution to the biology of caddisflies (Trichoptera) in temporary pools. Royal Ontario Museum Life Sciences Contributions 88: 1-28.

Wiggins, G. B., R. J. Mackay \& I. M. Smith, 1980. Evolutionary and ecological strategies of animals in annual temporary pools. Archiv für Hydrobiologie 58 (Suppl): 97-206.

Williams, D. D., 1987. The Biology of Temporary Waters. Timber Press, Portland, Oregon.

Williams, D. D., 2006. The biology of temporary waters. Oxford University Press, Oxford.

Wissinger, S., W. Brown \& J. Jannot, 2003. Caddisfly life histories along permanence gradients in high-altitude wetlands in Colorado (USA). Freshwater Biology 48(2): 255-270.

Wissinger, S., J. Steinmetz, J. S. Alexander \& W. Brown, 2004a. Larval cannibalism, time constraints, and adult fitness in caddisflies that inhabit temporary wetlands. Oecologia 138(1): 39-47. 
Wissinger, S. A., C. Eldermire \& J. C. Whissel, 2004b. The role of larval cases in reducing aggression and cannibalism among caddisflies in temporary wetlands. Wetlands 24(4): 777-783.

Wissinger, S. A., J. C. Whissel, C. Eldermire \& W. S. Brown, 2006. Predator defense along a permanence gradient: roles of case structure, behavior, and developmental phenology in caddisflies. Oecologia 147(4): 667-678.

Womersley, C. \& C. Ching, 1989. Natural dehydration regimes as a prerequisite for the successful induction of anhydrobiosis in the nematode Rotylenchulus reniformis. Journal of Experimental Biology 143(1): 359-372.

Young, J. O., 1976. The freshwater Turbellaria of the African continent. Zoologischer Anzeiger 197: 419-432.

Yozzo, D. \& R. Diaz, 1999. Tidal freshwater wetlands: invertebrate diversity, ecology, and functional significance. In Batzer, D. P., R. B. Rader \& S. A. Wissinger (eds) Invertebrates in freshwater wetlands of North America: ecology and management. Wiley, Hoboken, New Jersey, 889-918.

Zamora-Muñoz, C. \& B. Svensson, 1996. Survival of caddis larvae in relation to their case material in a group of temporary and permanent pools. Freshwater Biology 36(1): 23 - 